ACCEPTED MANUSCRIPT

\title{
Aggregation effects on the magnetic properties of iron oxide colloids
}

To cite this article before publication: Lucia Gutierrez et al 2019 Nanotechnology in press https://doi.org/10.1088/1361-6528/aafbff

\section{Manuscript version: Accepted Manuscript}

Accepted Manuscript is "the version of the article accepted for publication including all changes made as a result of the peer review process, and which may also include the addition to the article by IOP Publishing of a header, an article ID, a cover sheet and/or an 'Accepted Manuscript' watermark, but excluding any other editing, typesetting or other changes made by IOP Publishing and/or its licensors"

This Accepted Manuscript is @ 2019 IOP Publishing Ltd.

During the embargo period (the 12 month period from the publication of the Version of Record of this article), the Accepted Manuscript is fully protected by copyright and cannot be reused or reposted elsewhere.

As the Version of Record of this article is going to be / has been published on a subscription basis, this Accepted Manuscript is available for reuse under a CC BY-NC-ND 3.0 licence after the 12 month embargo period.

After the embargo period, everyone is permitted to use copy and redistribute this article for non-commercial purposes only, provided that they adhere to all the terms of the licence https://creativecommons.org/licences/by-nc-nd/3.0

Although reasonable endeavours have been taken to obtain all necessary permissions from third parties to include their copyrighted content within this article, their full citation and copyright line may not be present in this Accepted Manuscript version. Before using any content from this article, please refer to the Version of Record on IOPscience once published for full citation and copyright details, as permissions will likely be required. All third party content is fully copyright protected, unless specifically stated otherwise in the figure caption in the Version of Record.

View the article online for updates and enhancements. 


\section{Aggregation effects on the magnetic properties of iron oxide colloids}

Lucía Gutiérrez* ${ }^{* \Uparrow}$, Leonor de la Cueva ${ }^{\ddagger}$, María Moros $^{\S}$, Eva Mazarío ${ }^{\perp}$, Sara de Bernardo ${ }^{\S}$, Jesús

M. de la Fuente ${ }^{\S}$, M. Puerto Morales ${ }^{\perp}$, Gorka Salas* ${ }^{\ddagger}$

† Departamento de Química Analítica, Instituto de Nanociencia de Aragón, Universidad de Zaragoza and CIBER-BBN, Mariano Esquillor, s/n, 50018. Zaragoza, Spain.

§ Instituto de Ciencia de Materiales de Aragón-CSIC/Universidad de Zaragoza and CIBER-BBN, Spain.

$\ddagger$ IMDEA Nanociencia, C/Faraday, 9, 28049. Madrid, Spain.

${ }^{\perp}$ Instituto de Ciencia de Materiales de Madrid, CSIC, Sor Juana Inés de la Cruz 3, Cantoblanco, 28049 Madrid, Spain.

KEYWORDS. iron oxides, magnetic nanoparticles, surface coating, aggregation, nanomagnetism, magnetic hyperthermia, colloids. 


\section{ABSTRACT}

Magnetic nanoparticles, and in particular iron oxide nanoparticles (mainly magnetite and maghemite), are being widely used in the form of aqueous colloids for biomedical applications. In such colloids, nanoparticles tend to form assemblies, either aggregates, if the union is permanent, or agglomerates, if it is reversible. These clustering processes have a strong impact on the magnetic nanoparticles properties that are often not well understood.

In this review, the causes and consequences of magnetic nanoparticles aggregation/agglomeration are reviewed and discussed. Special attention has been paid to the impact of the magnetic nanoparticles aggregation/agglomeration on their magnetic properties and heating properties, when exposed to an alternating magnetic field in the frame of magnetic hyperthermia.

In addition, a model system with magnetic nanoparticles of two different sizes coated with three different molecules (oleic acid, meso-2,3-dimercaptosuccinic acid and poly(maleic anhydride-alt-1-octadecene) has been characterised and the results used to support the ideas reviewed. 


\section{Introduction}

Magnetic nanoparticles (MNPs) are among the most interesting and promising materials in the field of nanoscience, with some examples already in the market and other applications being investigated in different fields like biomedicine, catalysis, environment, data storage, sensing, rheology or magnetic inks. ${ }^{1,2,3}$ From all the possible different magnetic materials, those composed by magnetic iron oxides (mainly magnetite and maghemite) are especially relevant for the development of biomedical applications. This fact is a direct consequence of the existence of metabolic pathways able to transform the iron released from the particles into safe forms that can be further used by the organism. ${ }^{4}$ Hence, iron oxide MNPs have been able to reach the clinical practice through approval by regulatory agencies, such as the Food and Drug Administration (FDA) of the USA..$^{.5}$ The magnetic properties of these particles have allowed them to play a fundamental role in several biomedical applications. Among others, they are being studied as carriers in drug delivery systems, heat generators for cancer treatment by magnetic hyperthermia and contrast agents for magnetic resonance imaging (MRI).

These nanoparticles are generally used in the form of colloids, also termed dispersions (or sols for solid-liquid systems), that consist on particles with sizes between 1 and $1000 \mathrm{~nm}$ homogenously dispersed in a liquid medium whose properties depend on the size, shape, surface charge, conformational properties and interaction forces. ${ }^{6}$ For particulate systems in which the size exceeds $1 \mu \mathrm{m}$ it is usual to refer to them as suspensions, though the two terms are often used interchangeably. In the absence of specific coatings, MNPs that form part of a colloid tend to gather forming groups of several magnetic cores generally called aggregates or agglomerates (Fig. 1). ${ }^{7}$ These assemblies of MNPs may be caused by either strong or weak physical interactions. In the former case, the magnetic cores will remain together permanently forming 
aggregates, while in the second case, reversible processes may occur forming alterable agglomerates. These processes generally lead to a mixture of isolated nanoparticles and nanoclusters composed of a variable number of MNPs.

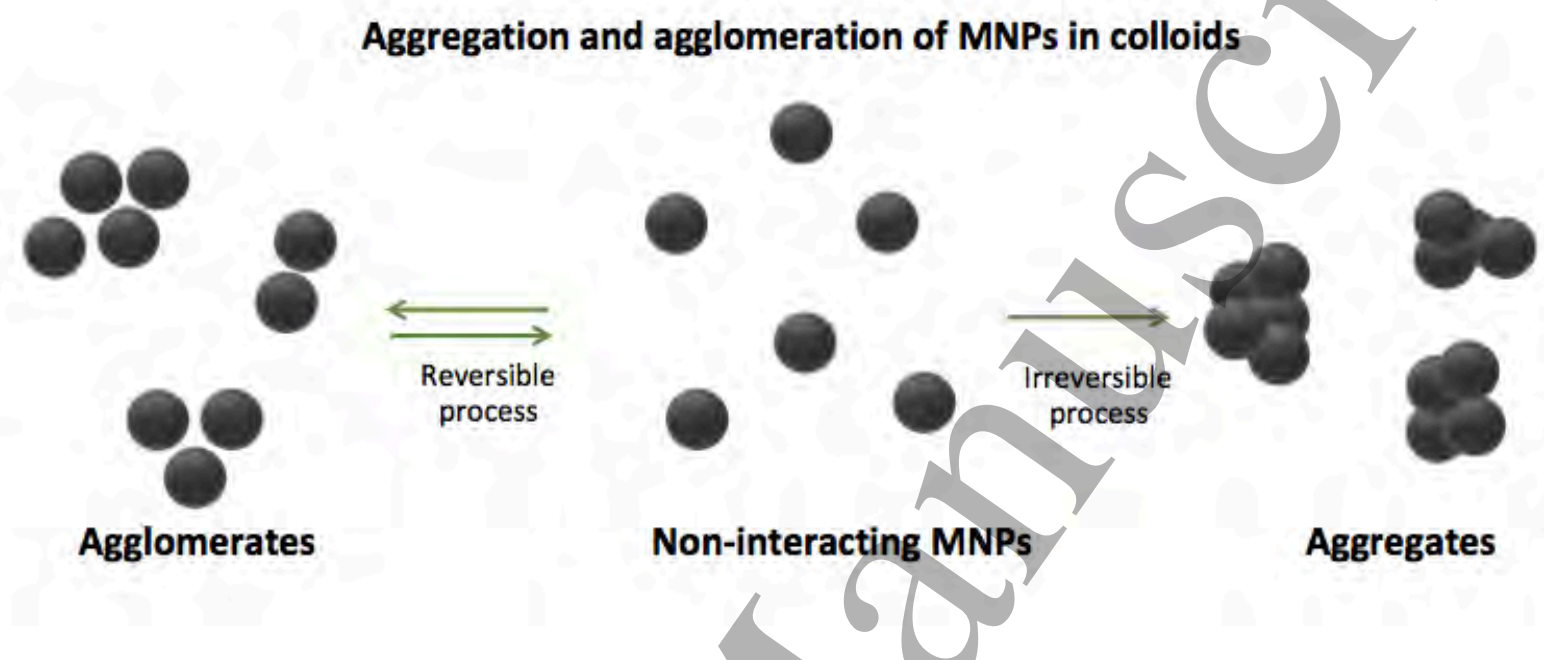

Figure 1. Schematic representation of the formation of the aggregation and agglomeration processes of MNPs in colloidal suspensions.

The clustering process is frequent and very often unavoidable when nanoparticles are dispersed in a liquid phase, ${ }^{8,9}$ whether if pre-synthesized hydrophobic MNPs are transferred to water or if they are directly obtained into it, for example by co-precipitation or hydrothermal synthesis. Moreover, although MNPs water phase stabilization is a necessary step, frequently it is not sufficient for providing MNPs stability in biological media. In fact, application of MNPs in biomedicine generally requires their contact with biological environments such as serum, blood or other physiological fluids, which are known to be extremely complex systems. These interactions of MNPs with components of biological system result in the formation of the socalled "biomolecule corona", of which protein corona (PC) is the one that has been mostly studied. Currently, it is accepted that PC formation is inevitable and that almost all MNPs once in contact with biological milieu will adsorb in some degree proteins. ${ }^{10}$ Hence, MNPs acquire a 
The aggregation/agglomeration of MNPs has a strong impact on the properties of the particles.

For example, in the case of multi-core particles, where several magnetic cores are assembled forming a defined structure, the separation between cores will strongly affect the magnetic 
interactions among them and therefore have a strong influence on the magnetic behaviour of the whole particle. There are other factors that influence the properties of MNPs and their potential use in many applications, such as their composition, shape and size distribution, but aggregation/agglomeration is particularly difficult to study, sometimes overlooked, and still not well understood.

This topical review aims at describing the interrelationship between the aggregation/agglomeration and the magnetic properties of iron oxide MNPs. Special attention is also paid to the consequences of aggregation/agglomeration in the frame of magnetic hyperthermia studies. In many cases, contradictory results are found in the literature as a result of the multitude of parameters that affect the magnetic properties of a given set of MNPs and the little attention being paid to standardization in the synthesis and characterisation. Therefore, in this review, in addition to a critical summary of already published results on the impact of aggregation/agglomeration on the magnetic and heating properties of nanoparticles, a model system has been prepared and characterized for comparison with the already existing data. Our model system is based on MNPs of different sizes (14 and $22 \mathrm{~nm}$ ) coated with different molecules. Particles with very narrow size distributions have been prepared by the same thermal decomposition method and with the same reactants and solvent, only differing in the temperature ramp, thus avoiding biased results due to different synthetic procedures. The as-prepared oleic acid coated MNPs (NP14ole, NP22ole) are hydrophobic and their surface has been modified to transfer them to water. For this purpose, two coatings, that are known by their extended use in biomedical applications have been chosen. ${ }^{23,24,25,26,27}$ Meso-2,3-dimercaptosuccinic acid (DMSA) has been used to prepare samples NP14DMSA and NP22DMSA; and poly(maleic anhydride-alt1-octadecene) (PMAO) has been used to prepare samples NP14PMAO and NP22PMAO. It is 
2

3

4

5

6

7

8

9

especially interesting that for each core size, the same batch of nanoparticles has been employed for all the coatings (Fig. 2). Along this work, we have also discussed one of the main problems that the research community working on MNPs for magnetic hyperthermia is facing, the lack of standardization procedures that allow an easy comparison of the results between different research groups.

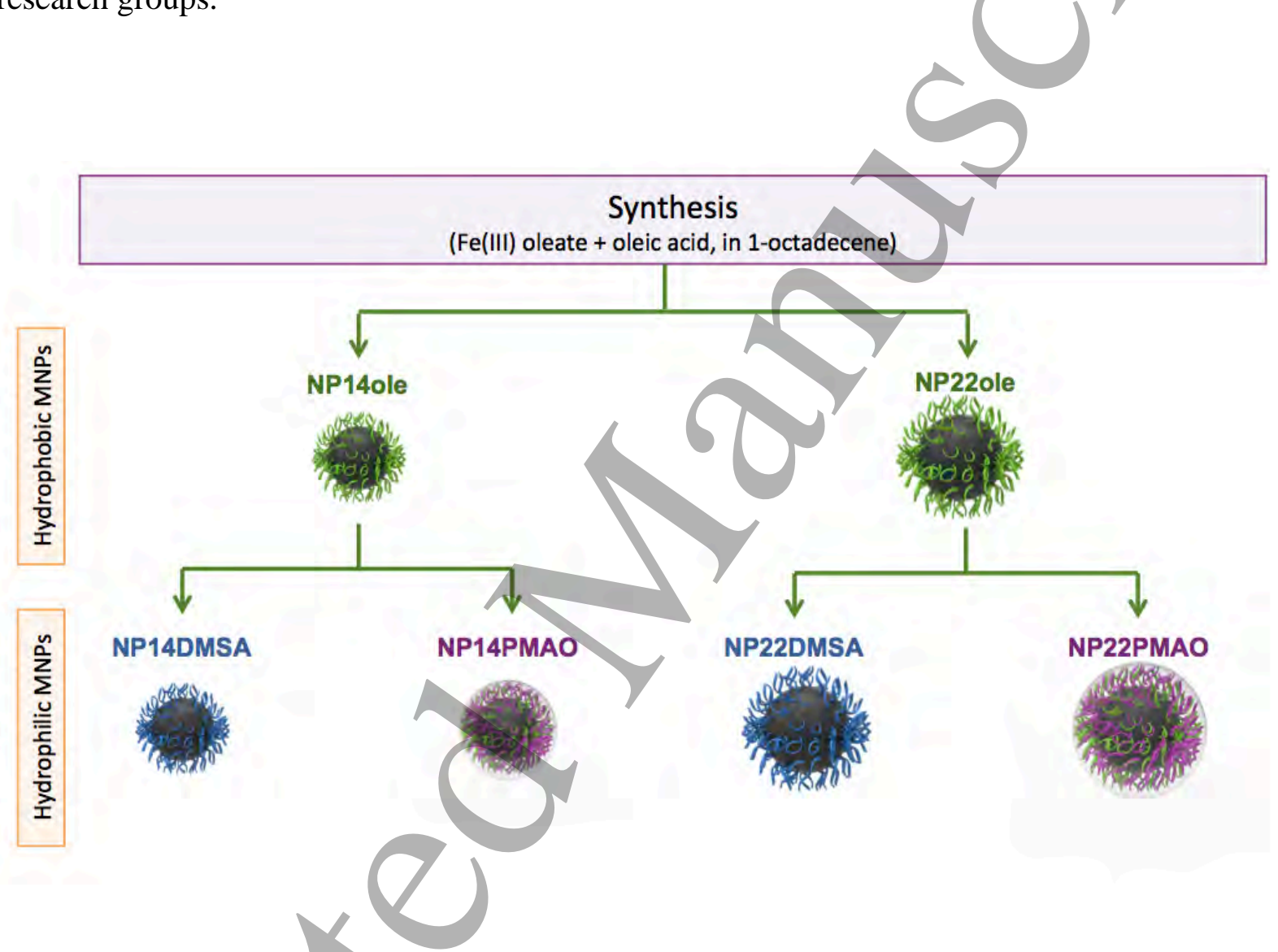

Figure 2. Simplified chart on the synthesis of the nanoparticles studied with the labels employed in this work. 


\section{MNPs coating: effect on the aggregation}

To stabilize the MNPs against agglomeration/aggregation and to provide biocompatibility, MNPs are coated with different molecules either during the synthesis (in situ) or in a different step after the synthesis. ${ }^{28,29}$ Small molecules or polymeric protective ligands such as DMSA, dextran, chitosan, PEG, poly(lactic-co-glycolic acid) (PLGA), are used to interact with the MNPs and reduce the interparticle surface interactions. ${ }^{30}$ Generally, MNPs modified with longer or bulkier ligands are more resistant to agglomeration than those modified with small ligands.

When the initial MNPs are hydrophobic, as those synthesized by thermal decomposition, two general approaches to render the MNPs hydrophilic are most frequently used. The first approach is the exchange of the surfactant (i.e. oleic acid) with another ligand molecule, that carries a functional group reactive toward the MNPs surface in one end, and in the other a hydrophilic group. ${ }^{42}$ The alternative approach is the addition of an amphiphilic ligand with one end being hydrophobic that will interact by hydrophobic interactions with the initial ligand that covers the surface of the MNPs; this way, the hydrophilic tail remains exposed into the aqueous solution, conferring hydrophilicity and stability (Fig. 3). 


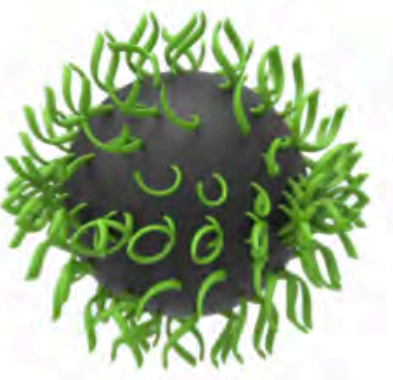

Ligand addition

Hydrophobic ligand (intercalation)

\title{
Hydrophobic ligand + \\ Amphiphilic ligand
}

\begin{abstract}
Figure 3. The most commonly used approaches to render MNPs hydrophilic. (up) Ligand exchange where hydrophobic surfactant molecules are replaced by molecules with hydrophilic groups. (down) Ligand addition where hydrophobic end of an amphiphilic ligand (e.g. polymer) intercalates in the hydrophobic molecules of the surfactant that covers NP and the hydrophilic part is exposed outside.

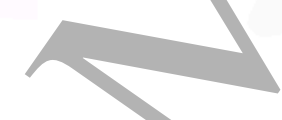

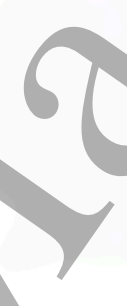

Hydrophilic ligand
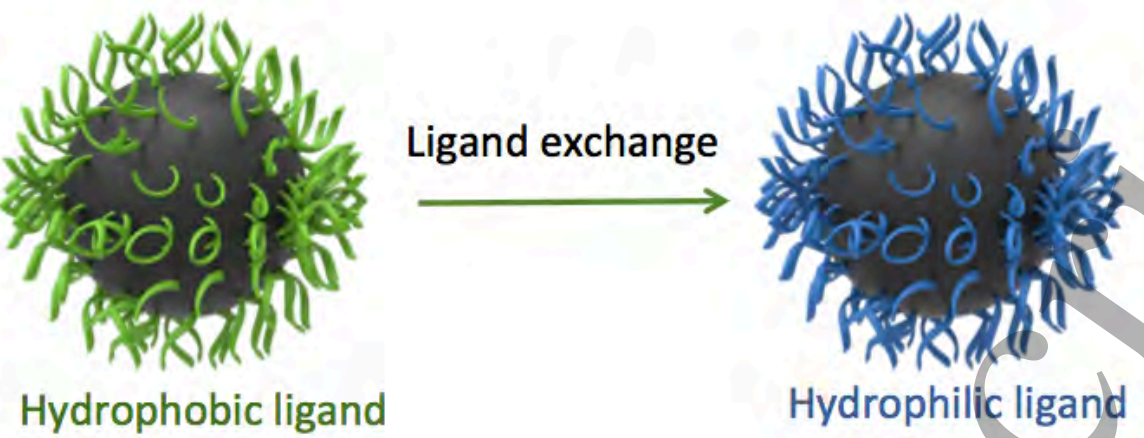

In the first approach, the binding ability of the ligand to the MNPs surface is crucial to ensure a stable dispersion. Typically, hydrophilic ligands with the anchoring groups such as dopamine (or its derivatives), ${ }^{31}$ carboxylic acids, ${ }^{32}$ phosphine oxides, ${ }^{33}$ or amines ${ }^{34}$ are employed as they 
generally have a good affinity for iron oxide surface. For example, PEG-derived phosphine oxide (PO-PEG) ligand has been demonstrated to displace oleic acid ligands in the MNPs synthesized by thermal decomposition, obtaining water-dispersible MNPs..$^{3}$ Similarly, DMSA forms a stable coating with the particles surface through its carboxylic chelate bonding. Further stabilization comes from the ligand cross-linking, by forming intermolecular disulphide cross-linkages among the bonded DMSA. ${ }^{35}$ This method renders MNPs with relatively low aggregation, and the hydrodynamic size can be almost unaltered if the ligand is small. One disadvantage is the possibility of agglomeration if the ligand bears other functional groups that can crosslink with those of other MNPs.

The second approach to modify hydrophobic MNPs is by addition of an intercalating ligand; PEGylated phospholipids and amphiphilic polymers (i.e. poly (maleic anhydride-alt-1octadecene, PMAO) are widely used as MNPs stabilizers. ${ }^{36}$ During the coating process, if the parameters are finely tuned, the agglomeration is almost avoided, ${ }^{13}$ although the hydrodynamic size is increased.

We have used our model system to study the influence of coating on the aggregation of the material. For this purpose, particles with two different sizes (14 and $22 \mathrm{~nm}$ ) coated with three different molecules have been selected (Fig. 2). Aggregation has been evaluated measuring the hydrodynamic diameter ( $\mathrm{D}_{\text {hyd }}$ ) by dynamic light scattering (DLS) of the as-prepared oleic acid coated MNPs, together with the same particles after surface modification with either DMSA or PMAO (Table 1, Fig. 4). Core sizes have also been measured by TEM ( $\left.\mathrm{D}_{\mathrm{TEM}}\right)$ for comparison with the hydrodynamic diameters (Table 1, Fig 5). In most cases, a monomodal distribution in intensity has been obtained in the $\mathrm{D}_{\text {hyd. }}$. 


\begin{tabular}{|l|c|c|}
\hline \multicolumn{1}{|c|}{ Sample } & $\begin{array}{c}\mathrm{D}_{\text {TEM }} \pm \text { s.d. } \\
(\mathrm{nm})^{(\mathrm{a})}\end{array}$ & $\begin{array}{c}\mathrm{D}_{\text {hyd }}, \text { PdI } \\
(\mathrm{nm})^{(\mathrm{b})}\end{array}$ \\
\hline NP14ole & $14 \pm 1$ & $15,0.15$ \\
\hline NP14DMSA & $14 \pm 1$ & $28,0.17$ \\
\hline NP14PMAO & $14 \pm 1$ & $46,0.27$ \\
\hline NP22ole & $22 \pm 3$ & $101,0.17$ \\
\hline NP22DMSA & $22 \pm 3$ & $101,0.14$ \\
\hline NP22PMAO & $22 \pm 3$ & $137,0.12$ \\
\hline
\end{tabular}

Table 1. Sizes of the samples ${ }^{(a)}$ Mean core size measured by TEM and standard deviation, ${ }^{(b)}$ aggregate size as $D_{\text {hyd, }}$ (Z-average) measured by DLS and polidispersity index (PdI).

MNPs coated with oleic acid and dispersed in hexane (NP14ole) exhibit a $\mathrm{D}_{\text {hyd }}$ of $15 \mathrm{~nm}$, almost the same as the inorganic core size measured by TEM, which means that there is no aggregation/agglomeration, or it is negligible, and the sample consists of single-core particles. However, 14 nm MNPs coated with DMSA (NP14DMSA) or PMAO (NP14PMAO) in water are slightly aggregated and the polidispersity index and the intensity vs. size curve of NP14PMAO suggest a non-modal distribution with a slightly larger aggregate size than NP14DMSA (Fig. 4, left).

The larger $22 \mathrm{~nm}$-core MNPs display very close values of $\mathrm{D}_{\text {hyd }}$ independently of the coating, slightly higher with PMAO again (Fig. 4, right). These results indicate that the initial stock dispersion of oleic-coated MNPs is already aggregated and that the subsequent processes of ligand exchange or polymer encapsulation are not reducing the size of the aggregates. The reason for this may lie in the bigger particle size that enhances the interactions among particles already with the initial oleic acid coating. Thus, the coating procedure occurs around the initial aggregates. 

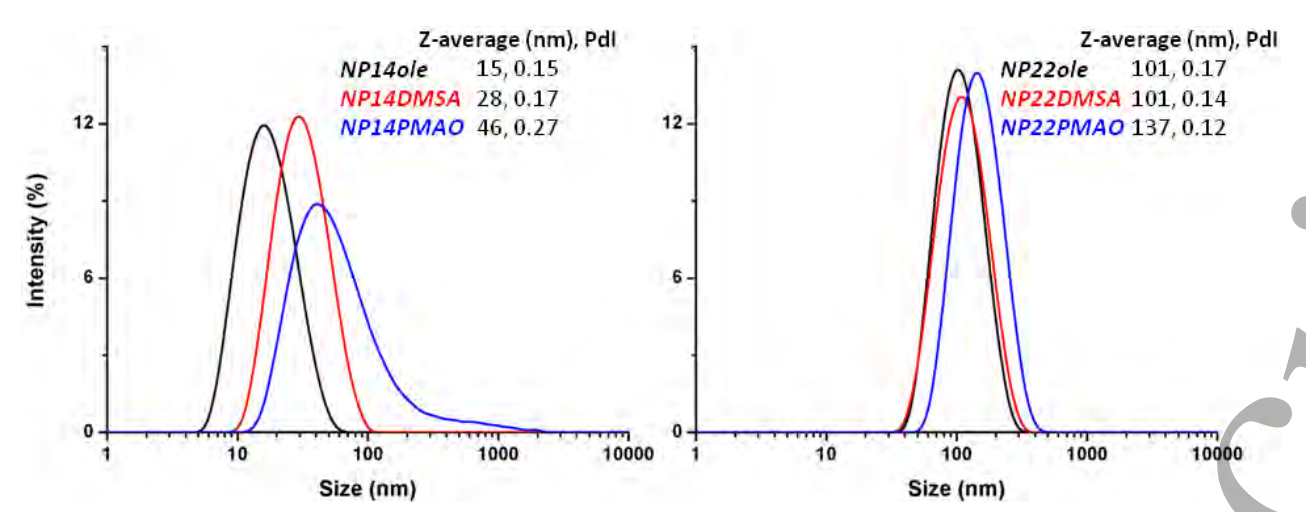

Figure 4. Hydrodynamic size distributions as a function of the coating for the nanoparticles with core size of 14 (left) and $22 \mathrm{~nm}$ (right).
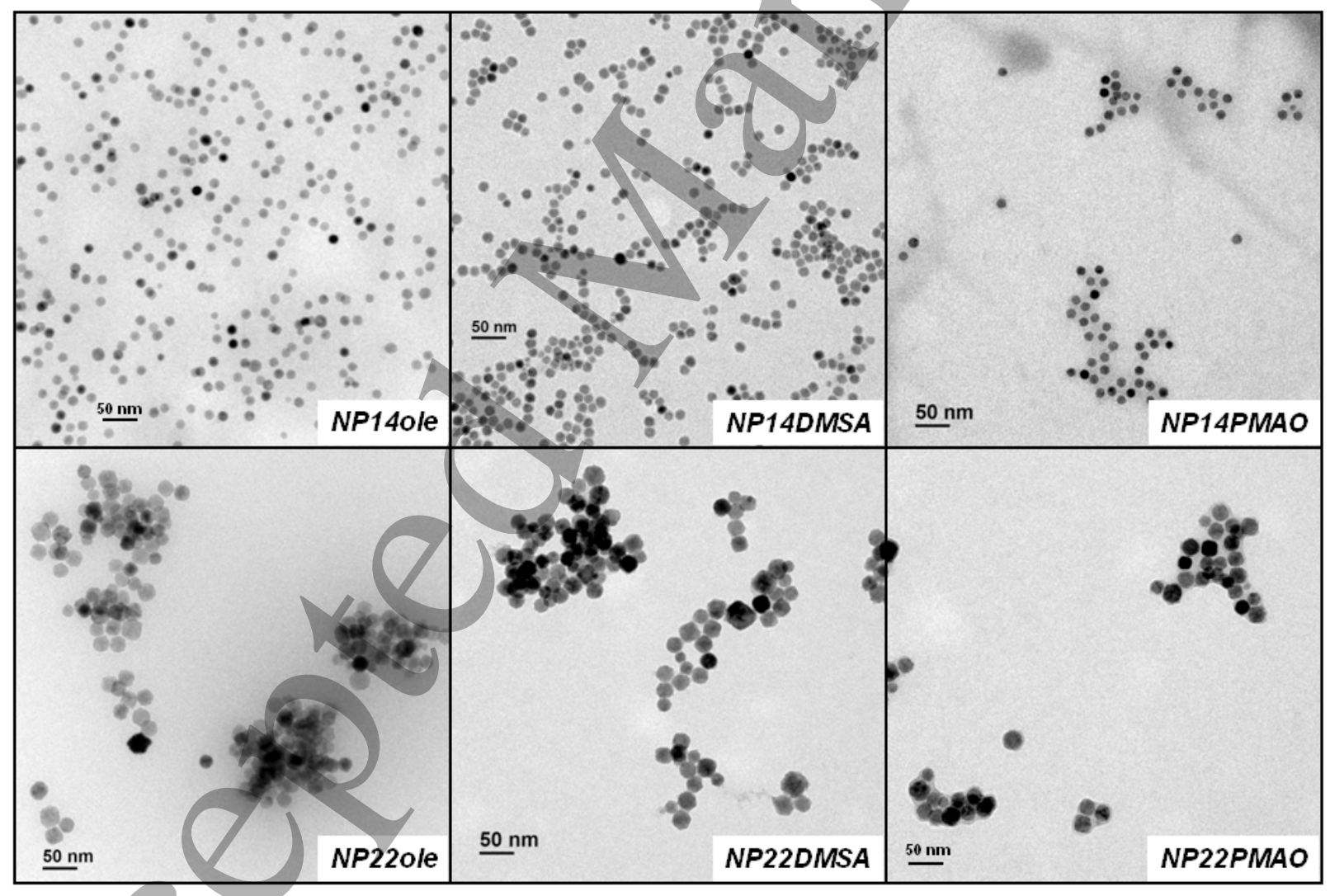

$50 \mathrm{~nm}$
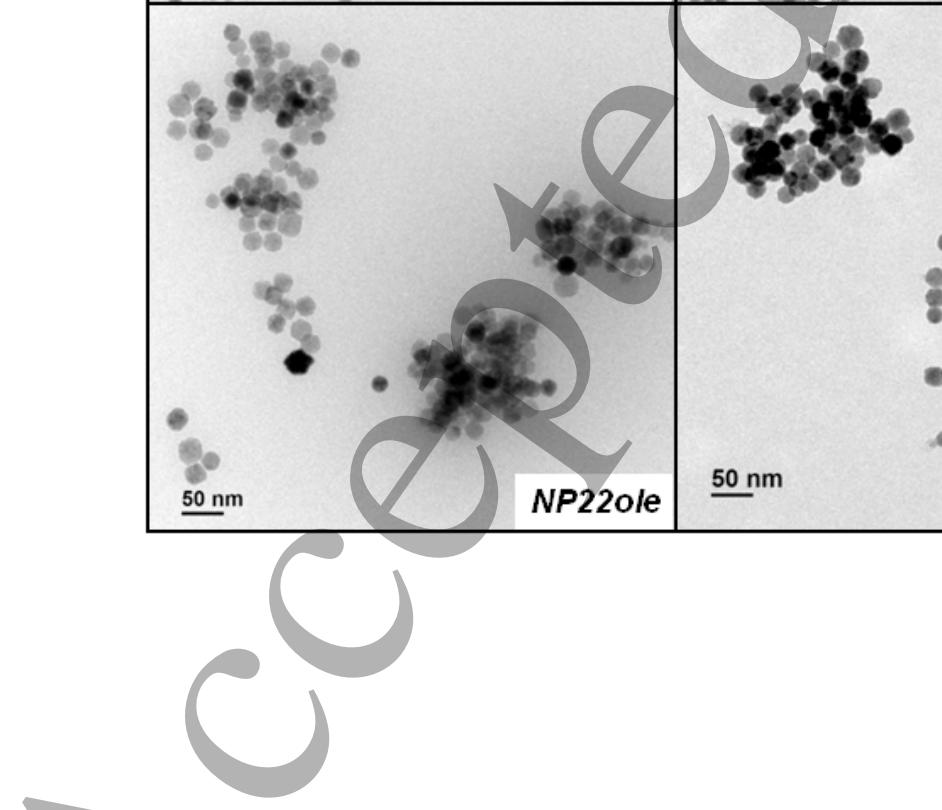

8


Figure 5. Selected TEM micrographs of the MNPs with core sizes of $14 \mathrm{~nm}$ (upper row) and 22 nm (lower row) coated, from left to right, with oleic acid, PMAO and DMSA. All images are at the same scale.

TEM results are qualitatively consistent with DLS measurements of aggregate size: isolated MNPs are observed in the NP14ole sample, while all the other samples show some degree of aggregation. In samples NP14DMSA and NP14PMAO, isolated particles (around $4 \%$ in both cases, as estimated from the TEM micrographs of Figure 6 and Section S1 of the supporting information) can be observed together with small aggregates formed by 2 or 3 particles and larger ones of around $100 \mathrm{~nm}$ that contain dozens of them. NP22ole sample, not subjected to surface modification, is already aggregated, in agreement with DLS results. NP22DMSA and NP22PMAO show similar aspects with even larger aggregates in the upper limit and a lower proportion of isolated particles than in the $14 \mathrm{~nm}$ samples (around $3 \%$ in NP22DMSA and $1 \%$ in NP22PMAO, as estimated from the TEM micrographs of Figure 3 and Section S1 of the supporting information).

In the TEM micrographs of the DMSA and PMAO samples the organic coating can be observed as a continuous layer covering the aggregates (Fig. 6), reinforcing the idea that during the process of transference to water aggregates, and not agglomerates, are formed. An interesting point about this observation is that the contribution of the organic coating to the size of the aggregate is relatively small if compared to the contribution of the core sizes forming it (see Fig. 6 and supplementary Section S1.3 and S1.4), even when considering non-aggregated particles. This is a very important feature to keep in mind when interpreting $\mathrm{D}_{\text {hyd }}$ values obtained by DLS 
or other means, because very often $\mathrm{D}_{\text {hyd }}$ values are used to deduce the thickness of the coating (subtracting TEM sizes from them). Our results show that aggregation is a plausible cause of the size increase that must be considered.

Comparing PMAO with DMSA for the $14 \mathrm{~nm}$ MNPs it seems that distances between individual MNPs within the aggregates are longer with the polymer (ca. $5 \mathrm{~nm}$ ) than with DMSA (ca. 1.5 $\mathrm{nm}$ ), as can be appreciated in Figure 6 and supplementary sections S1.1 and S1.2. By contrast, for the $22 \mathrm{~nm}$ MNPs the distance between individual MNPs in aggregates with both coatings seems to be very similar (Fig. 6).

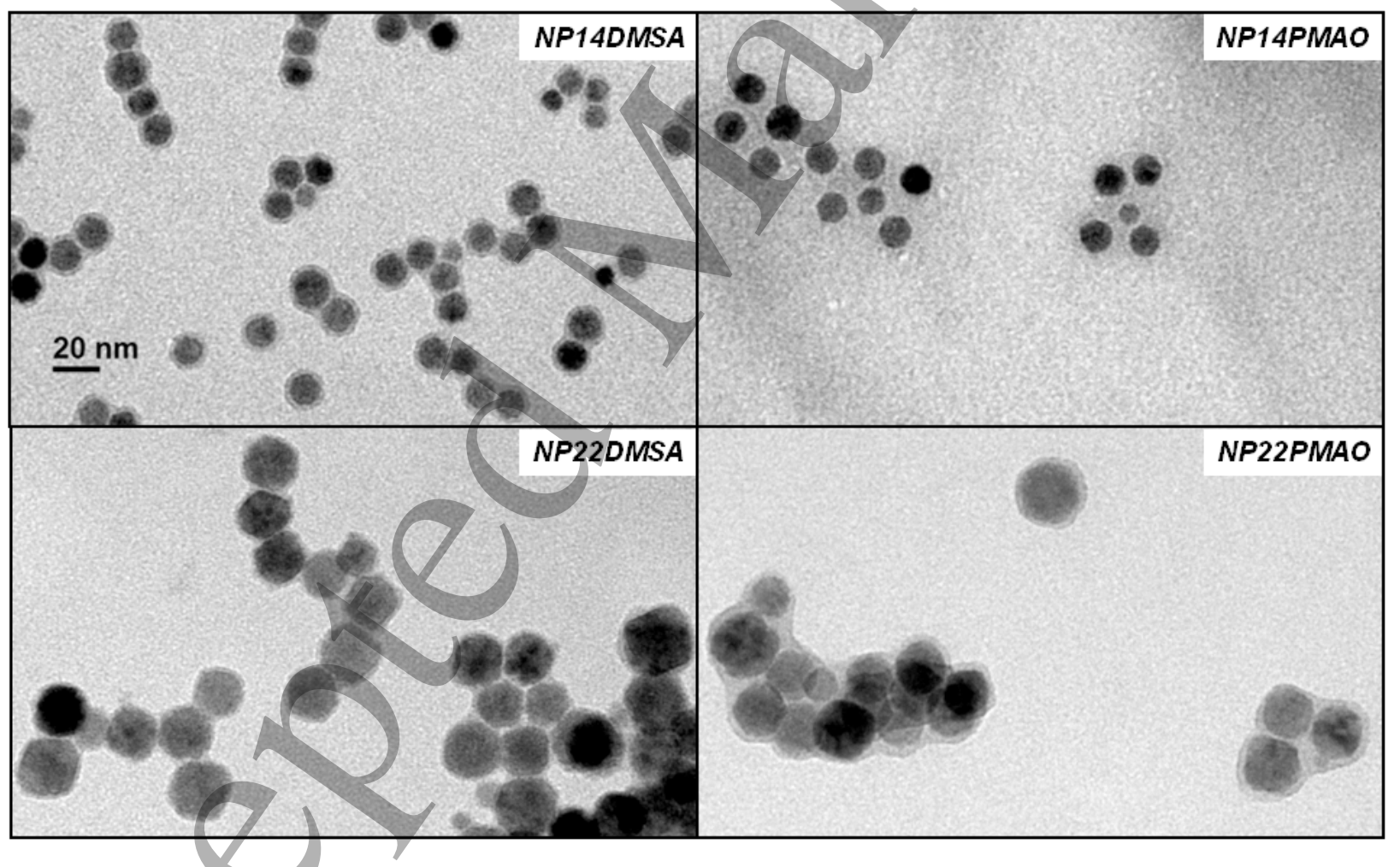


Figure 6. Selected TEM micrographs of the nanoparticles with core sizes of $14 \mathrm{~nm}$ (upper row) and $22 \mathrm{~nm}$ (lower row) coated with PMAO and DMSA. Organic coating can be observed with a light grey contrast around and between the darker iron oxide cores. All images are at the same scale.

Therefore, it can be concluded that when MNPs with the same core and even from the same batch are subjected to surface modification procedures, the MNPs may form aggregates with different sizes and arrangements.

\section{Magnetic interactions and their impact on the magnetic properties of the colloids}

In addition to the previously described forces among particles forming a colloid (electrostatic, Van der Waals, etc.), the case of MNPs stands out because of the existence of additional forces among the particles that appear as a consequence of their magnetic properties (Fig. 7). In particular dipole-dipole interactions or exchange interactions are favoured by aggregation or agglomeration processes and have a strong impact on the collective magnetic properties of the materials. Therefore, when interparticle distances decrease, these two types of interactions may appear resulting in the alteration of the magnetic properties when compared to a non-interacting system.

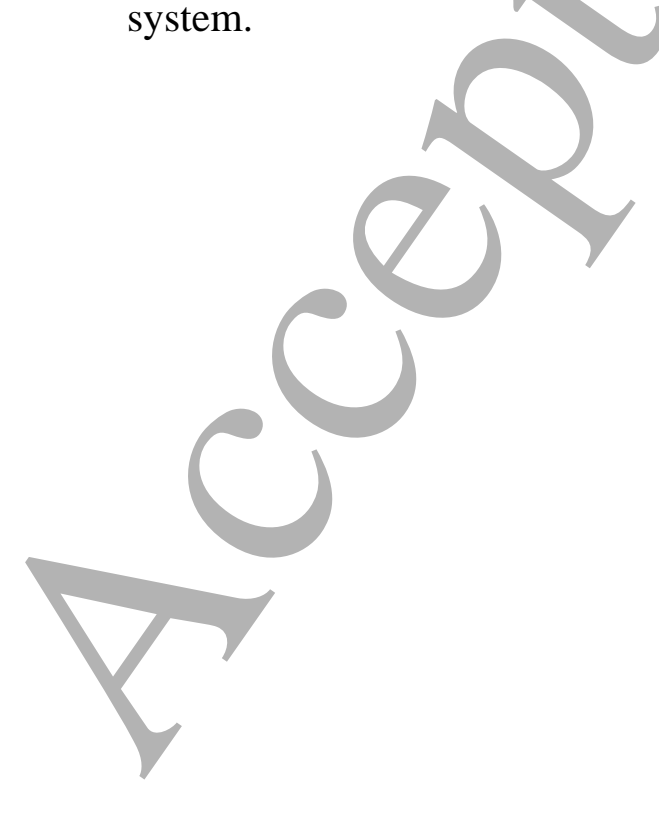




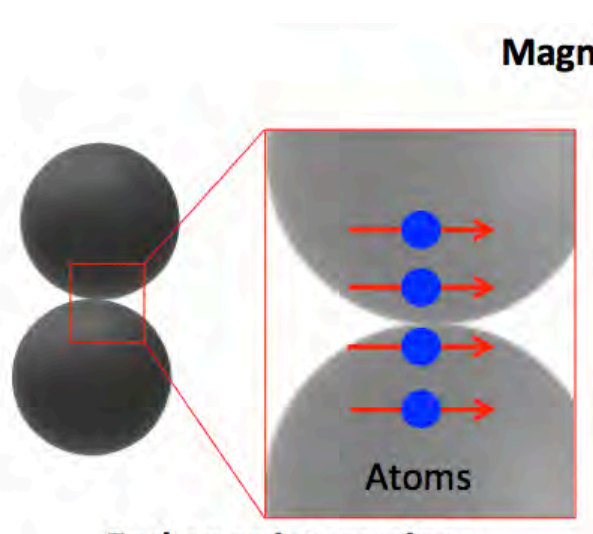

Exchange interactions

\section{interactions}

Figure 7. Schematic representation of the two types of magnetic interactions that occur among MNPs (Left) short-range exchange interactions and (Right) Long-range dipolar interactions.

Dipole-dipole interactions are long-range interactions whose strength depends on the interparticle distances. As a result of aggregation processes, these distances degrease, dipolar interactions increase and a collective magnetic state is formed. ${ }_{4{ }^{\mathrm{b}}}^{\mathrm{b}}$ Depending on the orientation of the particles forming the aggregate/agglomerate, either random orientation or with alignment of the magnetic moments (e.g. forming chains), the collective properties of the material may be significantly different. ${ }^{37}$

In particular, it has been shown that increasing dipole-dipole interactions can have a significant influence on DC (direct current) measurements, resulting on a change of the hysteresis loop, that depends on the nanoparticles arrangement (Fig. 8), ${ }^{38}$ and a shift of the ZFC (Zero Field Cooled) maximum towards higher temperatures when compared to non-interacting materials. ${ }^{39} \mathrm{~A}$ similar displacement of the blocking temperature appears also on AC (Alternating Current) measurements of interacting nanoparticles (Fig. 8). ${ }^{40}$ 

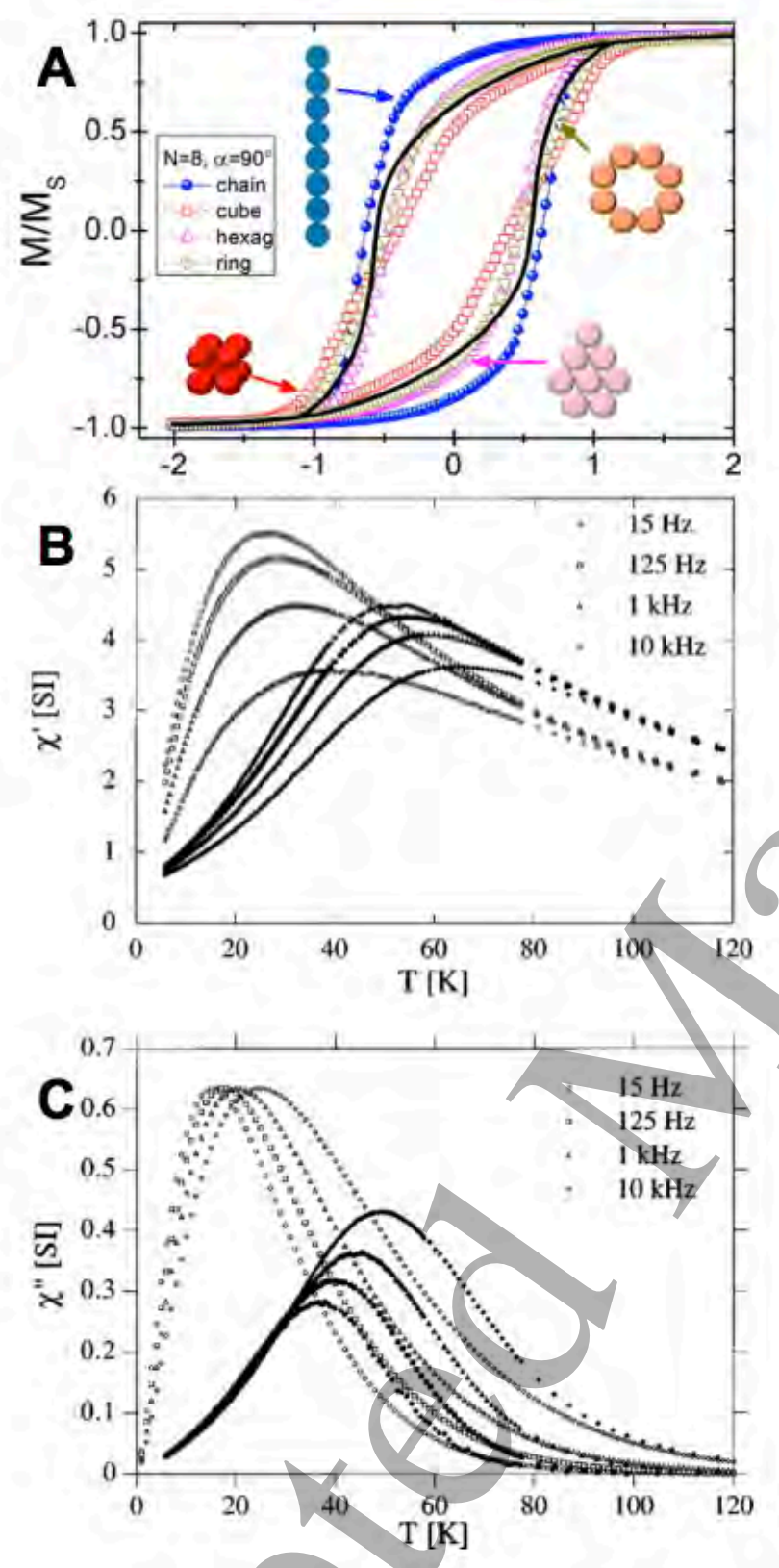

Fig. 8. (A) Field dependent magnetization curves corresponding to different spatial arrangements (bidimensional chain, hexagonal lattice, and ring; 3D cube) of the same amount of particles, $N=8$, and for the easy anisotropy axes randomly distributed into a cone of angle $\alpha=$ 90. The black line stands for the case of noninteracting particles. Reprinted with permission from ref. 38b. (B and C) Temperature dependence of the (B) In phase and (C) Out-of-phase 
susceptibility at different frequencies ranging from $15 \mathrm{~Hz}$ to $10 \mathrm{kHz}$ for noninteracting (open symbols) and interacting (solid symbols) $\quad \gamma-\mathrm{Fe}_{2} \mathrm{O}_{3}$ nanoparticles. Reprinted Figure with permission from ref. $40 \mathrm{~b}$.

Exchange interactions involve the coupling of the magnetic moments from two neighbour atoms in a quantum mechanical way, forcing their magnetic moments to align either in a parallel or antiparallel way. This type of interactions is especially relevant in the case of multi-core particles prepared directly with a controlled aggregation of the cores forming nanoflowers. ${ }^{41}$ In these materials, there is a crystal continuity at the core interfaces that allows a cooperative behaviour due to exchange interactions between the cores, resulting in an enhanced susceptibility while maintaining superparamagnetic behaviour. ${ }^{42}$ Exchange interactions are also responsible for the displacement of the blocking temperature in comparison with non-interacting nanoparticles. ${ }^{43}$ Interestingly, it has been reported that the same MNPs without coating or coated with DMSA present very different aggregation with small differences in DC magnetization measurements in solid state, but largely different magnetic moments when they are measured in liquid dispersion through a method relating the magnetic force and the movement of a droplet under a magnetic field gradient. ${ }^{44}$

In conclusion, magnetic interactions between particles become a critical factor that affects the magnetic properties of the materials and, thus, the applications of MNPs. ${ }^{45,46}$ This is especially relevant in the case of biomedical applications where particles may end up enclosed in cellular endosomes where they are highly concentrated, and therefore the magnetic interactions between them become very strong. 
To study only the influence of coating on the aggregation and therefore the magnetic properties of the material, particles with two different sizes (14 and $22 \mathrm{~nm}$ ) and three coatings (ole, DMSA and PMAO) from our model systems (Fig. 1) were magnetically characterized. The magnetic properties have been measured on highly diluted samples, so agglomeration due to concentration was avoided. All the samples display superparamagnetic behavior (Fig. 9) at room temperature and similar coercivity at $5 \mathrm{~K}$ (NP14ole: 430 Oe; NP14DMSA: 345 Oe; NP14PMAO: 375 Oe; NP22ole: 330 Oe; NP22DMSA: 315 Oe; NP22PMAO: 330 Oe). Field dependent magnetization, $\mathrm{M}(\mathrm{H})$, curves at $5 \mathrm{~K}$ and room temperature do not show any variation due to the coating (Fig. 9). Mass susceptibilities calculated from the $\mathrm{M}(\mathrm{H})$ curves are slightly larger with PMAO and DMSA than with oleic acid, for a given core size (Table 2) indicating collective behavior for particles within the aggregates and that PMAO and DMSA coated particles within the aggregate are in closer contact.

\begin{tabular}{|l|c|c|c|}
\hline \multicolumn{1}{|c|}{ Sample } & $\chi_{\text {mass }}\left(\mathrm{m}^{3} \cdot \mathrm{kg}^{-1}\right)^{(\mathrm{a})}$ & $\begin{array}{c}\mathrm{T}_{\mathrm{B}, \mathrm{DC}} \\
(\mathrm{K})^{(\mathrm{b})}\end{array}$ & $\begin{array}{c}\mathrm{K}_{\mathrm{anis}} \\
\left(10^{4} \cdot \mathrm{J} \cdot \mathrm{m}^{3}\right)^{(\mathrm{c})}\end{array}$ \\
\hline NP14ole & 0.0008 & 190 & 4.6 \\
\hline NP14DMSA & 0.0014 & 210 & 5.0 \\
\hline NP14PMAO & 0.0014 & 220 & 5.3 \\
\hline NP22ole & 0.0004 & n.d. & n.d. \\
\hline NP22DMSA & 0.0021 & n.d. & n.d. \\
\hline NP22PMAO & 0.0022 & n.d. & n.d. \\
\hline
\end{tabular}

Table 2. Magnetic properties of the samples: ${ }^{(a)}$ mass susceptibility $\left(\chi_{\text {mass }}\right)$ obtained from the slopes of the $M(H)$ curves measured by VSM, ${ }^{(b)}$ blocking temperature $\left(T_{B, D C}\right)$ as the maximum of the ZFC curves measured by VSM, ${ }^{(c)}$ anisotropy constant $\left(K_{\text {anis }}\right)$ estimated from $T_{B, D C}$ values through the expression $K_{\text {anis }}=25 k_{b} T_{B, D C} / V\left(k_{b}=\right.$ Boltzmann constant, $V=$ volume of the particle assuming spherical shape). 

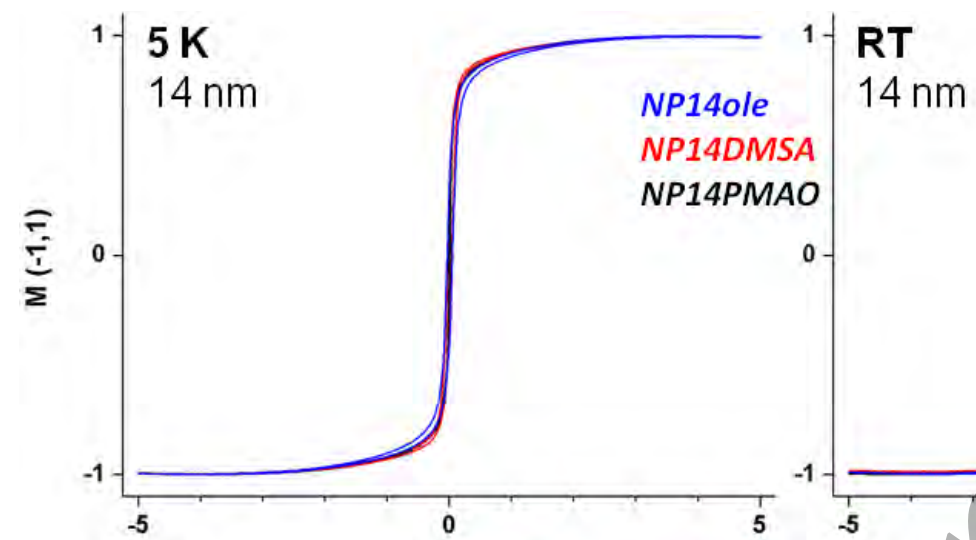
$14 \mathrm{~nm}$

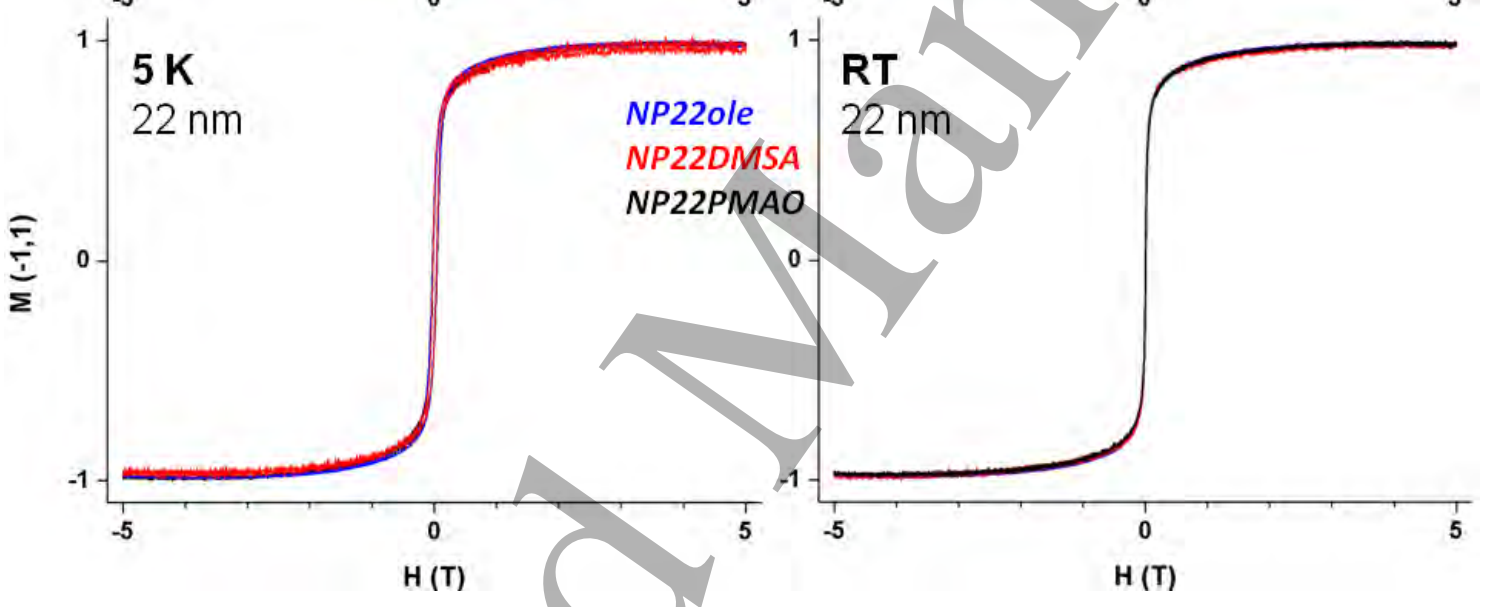

Figure 9. Field dependent magnetization at $5 \mathrm{~K}$ and room temperature (r.t.) of the $14 \mathrm{~nm}$ (up) and $22 \mathrm{~nm}$ (down) MNPs coated with oleic acid (blue), PMAO (black) and DMSA (red). For a given size, there are no apparent differences between particles with different coatings.

From Zero-field-cooled (ZFC) and field-cooled (FC) measurements of Figure 10, higher blocking temperatures $\left(\mathrm{T}_{\mathrm{B}}\right)$ are observed for the larger aggregate sizes determined by DLS, following the trend NP14PMAO $(220 \mathrm{~K})>$ NP14DMSA $(210 \mathrm{~K})>$ NP14ole $(190 \mathrm{~K})$. These 
results are also consistent with TEM observations and the mass susceptibilities calculated from the $\mathrm{M}(\mathrm{H})$ loops $(\mathrm{NP14PMAO}=\mathrm{NP14DMSA}>\mathrm{NP14ole})$ (Table 2). These data agree with the expected tendency of shifting $\mathrm{T}_{\mathrm{B}}$ to higher temperatures with increasing dipole interactions mentioned before. ${ }^{47}$ It has not been possible to determine the blocking temperature of the $22 \mathrm{~nm}$ particles from the ZFC/FC curves as their maximum is out of the measured temperature range.
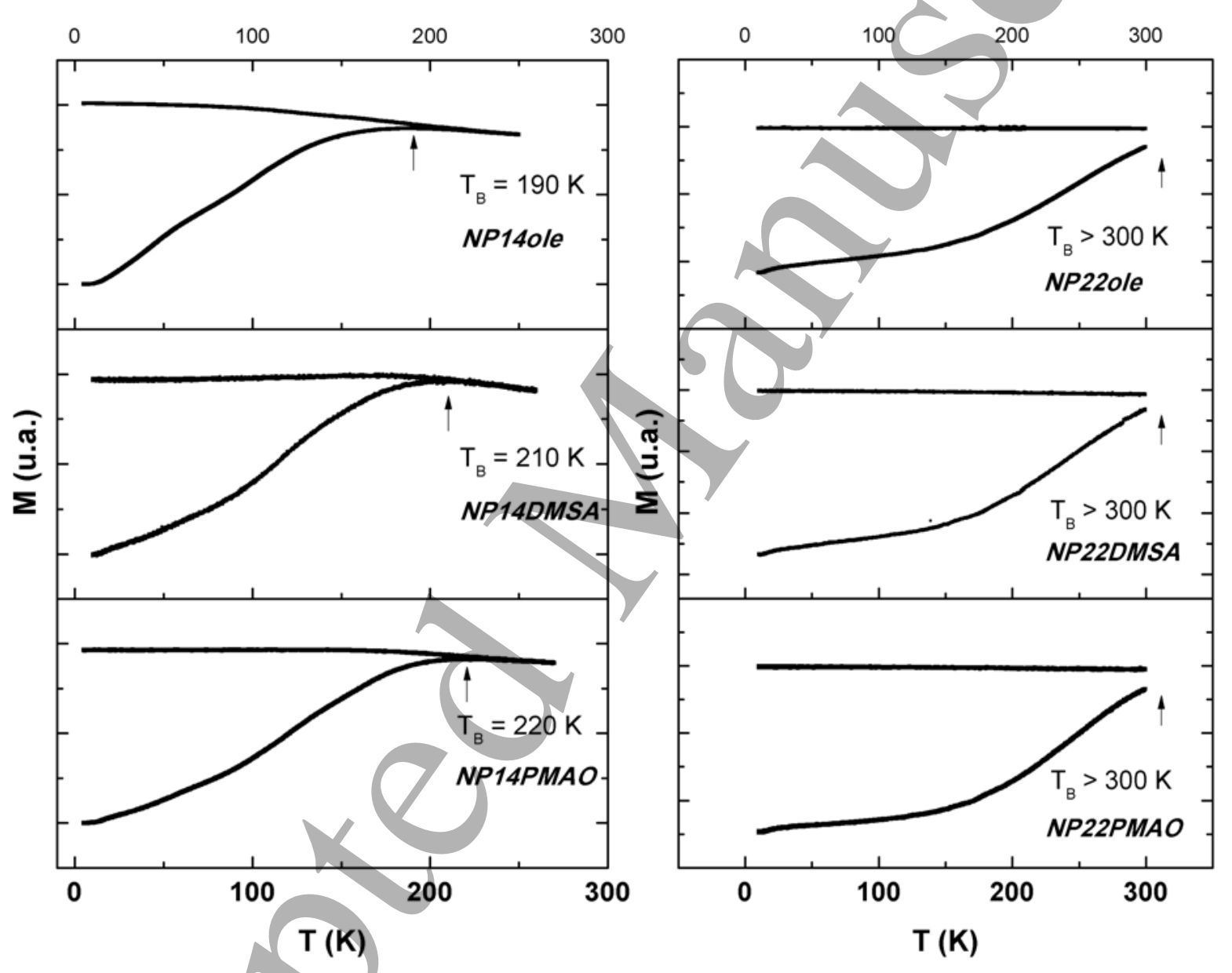

Figure 10. ZFC/FC of the $14 \mathrm{~nm}$ (left) and 22 (right) samples. From top to bottom: oleic, PMAO and DMSA coatings. Blocking temperatures $\left(T_{B}\right.$, as the maximum of the ZFC curve, indicated with an arrow) change with aggregate size, in the $14 \mathrm{~nm}$ MNPs following the trend: NP14ole < NPI4DMSA < NP14PMAO. Blocking temperature is not reached at $T \leq 300 \mathrm{~K}$ in the $22 \mathrm{~nm}$ MNPS. 
In AC magnetic susceptibility measurements, the smaller particles $(14 \mathrm{~nm})$, presented a in phase susceptibility $\left(\chi^{\prime}\right)$ maximum, accompanied by an out-of-phase susceptibility ( $\chi$ ”) maximum at slightly lower temperatures, indicative of a magnetic relaxation phenomenon of magnetic blocking of superparamagnetic particles. The temperature dependence of the out-of-phase susceptibility, $\chi$ ”(T), becomes zero at $300 \mathrm{~K}$ for particles with both coatings, indicating that these samples are superparamagnetic at room temperature (Figure 11). As in the ZFC/FC curves, the complete maximum, associated to the magnetic relaxation phenomenon, was not observed for the larger particles $(22 \mathrm{~nm}$ ), having a positive value for the out-of-phase susceptibility at $300 \mathrm{~K}$ (Figure 11).

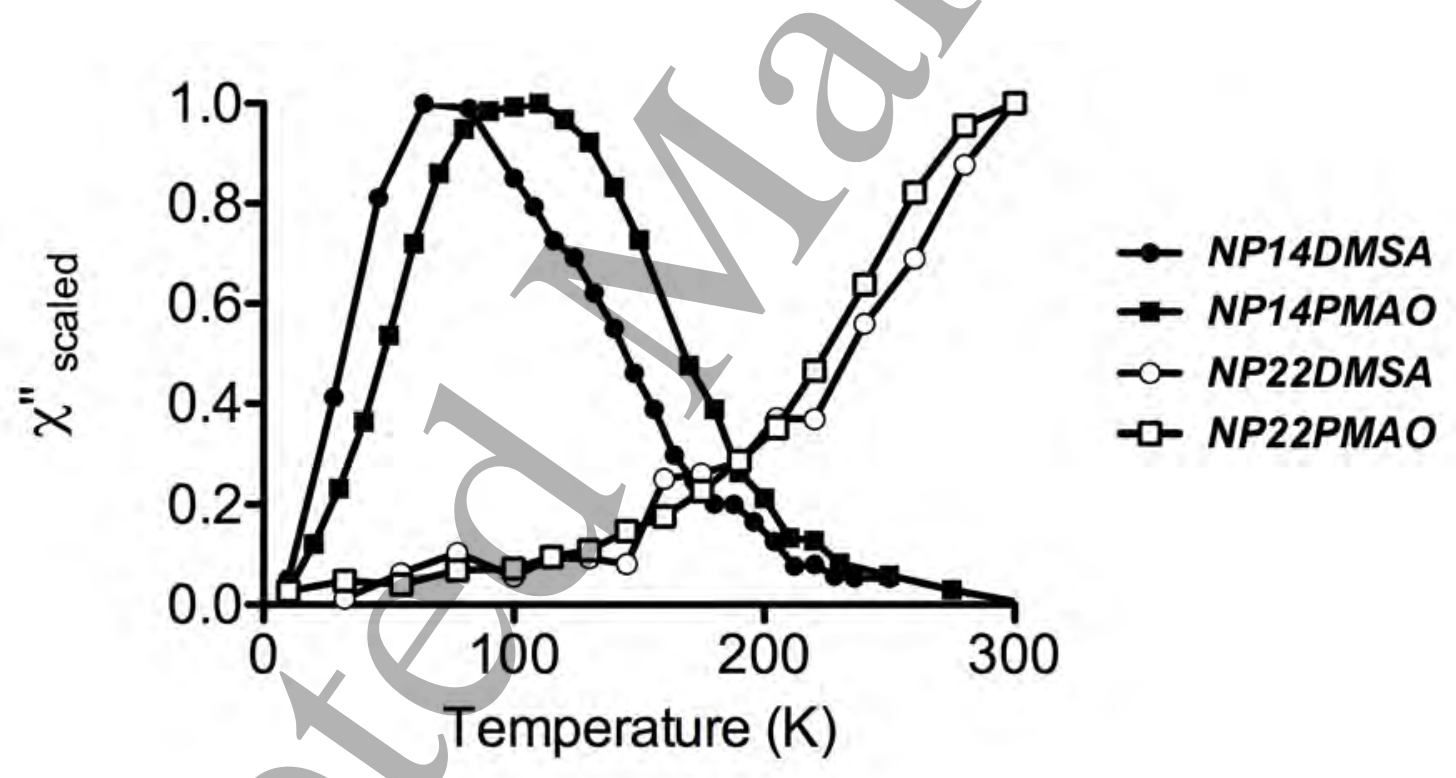

Figure 11. Temperature dependence of the out-of-phase susceptibility ( $\left.\chi^{\prime \prime}\right)$ scaled to its maximum. 
The $\chi$ " (T) profile can be interpreted as a measure of the interaction degree, because all the particles would have the same particle size distribution and effective anisotropy. In the case of NP14DMSA and NP14PMAO, diluted in agar to diminish the degree of magnetic interactions between aggregates, the $\chi$ ' $(\mathrm{T})$ maxima are located $\mathrm{T}=70 \mathrm{~K}$ and $100 \mathrm{~K}$, respectively (Figure 11). These results indicate that for this specific core size, PMAO particles show a higher degree of dipolar interactions among the cores. These results show a good correlation with the DLS analysis showing larger aggregate sizes with PMAO than with DMSA. The strength of magnetic interactions is influenced by the number of particles into the aggregates, the number of particles close enough to interact: therefore larger aggregates have more MNPs closer, so magnetic interactions are stronger.

From the results of our model systems, it can be concluded that in this case, with the relatively small clusters studied in this work (average size </200 nm), small differences in aggregation cause differences in magnetic properties such as AC susceptibility, coercivity or blocking temperatures.

\section{The case of magnetic hyperthermia: effect of the aggregation on the heating properties}

MNPs are being used in the frame of localized cancer treatment given their capacity to produce heat under the exposure of an alternating magnetic field (AMF). MNPs localized in the tumour area are able to induce cell death or alter the growth and differentiation of the cancer cells through the increase of the local temperature. 
The heat generated by MNPs under AMF is influenced by different parameters such as the size, shape, crystal structure, saturation magnetization, and magnetic susceptibility. In addition, it has been largely demonstrated that magnetic heating is affected by particle distribution, coating, surrounding environment, confinement or aggregation, among other factors that can affect magnetic relaxation processes and, therefore, heating capabilities. ${ }^{46}$ Therefore, it is important to know the effect of aggregation or agglomeration processes that affect the heating properties of the materials. However, only relative few studies have investigated the clustering effects and the formation of particle arrangements of defined geometries that may take place when the colloid is under the action of a magnetic field. ${ }^{48}$

The effect of clustering on magnetic properties due to surface modification has been studied comparing hydrophobic MNPs as directly obtained by the thermal decomposition method with the same MNPs after water transfer with DMSA. In all cases, nanoclustering of MNPs with randomly oriented easy axes affects the blocking temperature and is detrimental to their heating ability (evaluated through the specific absorption rate, SAR, of the nanoparticles). ${ }^{49}$ Magnetic interactions have been studied changing the concentration of MNPs in liquid or gel dispersions. An increase in concentration causes a reduction of the average inter-particle or inter-aggregate distance and previously reported examples have shown a non-monotonic dependence of the heating ability with concentration, attributed to the influences of the effective magnetic anisotropy and dipolar interactions. ${ }^{50}$ Experimental evidences and Monte Carlo modeling have also revealed the effects of the concentration on the magnetic susceptibility and hysteresis losses of ferromagnetic particles, thus implying a considerable reduction in specific heating power because of the interparticle aggregation with the concentration. ${ }^{.3^{a}}$ 
In the same way, chain like arrangement driven by anisotropic interactions of MNPs when aligned with the magnetic field, was reported to improve SAR values in comparison with the randomly distributed system. ${ }^{3 \mathrm{~b}}$ Experimental calorimetric measurements on $44 \mathrm{~nm}$ ferromagnetic spherical magnetite nanoparticles forming long chain configuration in high agar viscosity media oriented by a magnetic field revealed that the area of the hysteresis loops increases with the length of the chain because of the preferential orientation along the chain due to dipolar coupling. After some length (around 8 particles) further chain growth do not show heating performance improvement. This model also showed how centrosymmetric assemblies composed of eight nanoparticles renders smaller hysteresis loops in comparison with the chain like configuration. A qualitatively similar enhancement in SAR values was observed when magnetic 
nanospheres of $200 \mathrm{~nm}$ were aligned and immobilized in a hydrogel. ${ }^{53}$ In that case, heating was higher when the alternating magnetic field was parallel to the nanosphere alignment than perpendicular to it and, in both cases, higher than with non-aligned nanospheres. Experiments with layer-by-layer two-dimensional assemblies of $12 \mathrm{~nm}$ maghemite nanoparticles suggest that energy flux density vector is playing an important role in the observed behaviour with assembled MNPs and oriented alternating magnetic fields. ${ }^{54}$

Finally, the influence of agglomeration on magnetic properties and heating efficiency have been studied through changes in the $\mathrm{pH}$ or the salt content of the medium, which affects the colloidal stability of nanoparticle dispersions and can be controlled, to some extent, in order to prepare agglomerates of defined average sizes. ${ }^{555_{45} \mathrm{fh}}$ Inter- (long distance) and intra-aggregate (short distance) interactions resulted in magnetizing and demagnetizing effects, respectively and consequently, the heat dissipation power under AMF strongly reflects such different interacting phenomena. In fact, the increase in aggregate size leads to a progressive reduction of SAR values related to demagnetizing effects mediated by intra-aggregate dipolar interactions. ${ }^{45^{\mathrm{h}}}$

The heating properties of the 14 and $22 \mathrm{~nm}$ nanoparticles coated with either DMSA and PMAO (Fig. 1) from our model systems have been measured. An AMF (f = 838 kHz, H=20.05 kA/m) and a concentration of $0.5 \mathrm{mg} / \mathrm{mL}$ have been used. This concentration was chosen as it has been discussed that an increase of the concentration can lead to an increase of interparticle interactions and a decrease in SAR values. ${ }^{50}$ The $14 \mathrm{~nm}$ nanoparticles, either coated with PMAO and DMSA, present the same SAR values $(20 \mathrm{~W} / \mathrm{g})$. This indicates that neither the coating nor the differences that it causes in the magnetic properties have a noticeable effect on the heating capabilities of the nanoparticles with the smaller cores of around $14 \mathrm{~nm}$. Different results have been published by Coral et al. for MNPs with $10 \mathrm{~nm}$ and $18 \mathrm{~nm}$ of core size and with larger aggregate sizes and 
lower SAR values after the particles were coated with DMSA. ${ }^{49}$ The reason for the different relationship between aggregate sizes and SAR values observed in those works (inverse correlation) and in our case for the $14 \mathrm{~nm}$ MNPs (no correlation) may lie in the different applied field conditions $\left(\mathrm{H}=15.4 \mathrm{kA} / \mathrm{m}\right.$ and $\mathrm{f}=435 \mathrm{kHz}$ in Ludwig et al.; ${ }^{56} 52.0 \mathrm{kA} / \mathrm{m}$ and $260 \mathrm{kHz}$ or $35.6 \mathrm{kA} / \mathrm{m}$ and $145 \mathrm{kHz}$ in Coral et al. $\left.{ }^{49}\right)$ compared with the present work $(\mathrm{H}=20,05 \mathrm{kA} / \mathrm{m}$ and $\mathrm{f}$ $=838 \mathrm{kHz}$ ) or in the concentration used during the SAR measurements, that were much more diluted in our case $(0.5 \mathrm{mg}$ of Fe per $\mathrm{mL}$ for more than $3 \mathrm{mg}$ of Fe per mLin the case of Coral et al.) to avoid inter-aggregate interactions. Nevertheless, although with the present data this issue cannot be unambiguously clarified, a more plausible reason is that the alternating field amplitude used, $20.05 \mathrm{kA} / \mathrm{m}$, is enough to cause a maximum in the hysteresis cycle $\mathrm{M}(\mathrm{H})$ in both cases. It is known that the heating takes place when the alternating field conditions can turn the initially reversible $M(H)$ superparamagnetic behavior to an irreversible hysteretic one, and that the SAR value obtained is proportional to the hysteresis area. Given that aggregate sizes of NP14DMSA and NP14PMAO, even if different, are both very small (28 and $46 \mathrm{~nm}$, respectively), it is possible that the field amplitude used exceeds the amplitude needed to reach the maximum in both cases.

For the particles with the larger core size $(22 \mathrm{~nm})$, the SAR value obtained with the NP22PMAO coating $(175 \mathrm{~W} / \mathrm{g})$ is smaller than for the NP22DMSA $(221 \mathrm{~W} / \mathrm{g} \mathrm{Fe})$ which means that, under the AMF conditions used here, the slightly lower aggregate size in NP22DMSA (101 nm) compared with NP22PMAO (137 nm) has an impact on the SAR value. The dipolar interactions in the aggregates of $22 \mathrm{~nm}$ nanoparticles are detrimental for the heating abilities of the particles and are arguably more important in the system with the larger aggregate size. In contrast with $14 \mathrm{~nm}$ MNPs, the inverse correlation between aggregate sizes and SAR values observed with the $22 \mathrm{~nm}$ 
cores is consistent with the previous report by Coral et al., ${ }^{49}$ comparing oleic-coated MNPs and the same particles after ligand exchange with DMSA. Other authors compared particles with magnetic cores obtained from the same synthesis that were further coated with three different phosphorylated PEG coatings. Those three coatings yielded MNPs with different hydrodynamic sizes that were inversely correlated to the SAR values as well. ${ }^{57}$ Although those results also concur with our observation for the $22 \mathrm{~nm}$ MNPs, in that work the very plausible relationship of the measured hydrodynamic size and the degree of aggregation was not considered and the differences of SAR values were explained as due to an inhibition of the Brownian relaxation caused by the different lengths of the polymers used in the coatings.

From the results of our model system, it can be concluded that the differences in the degree of aggregation, even if they are small, can play an important role in the heating capabilities of MNPs under an AMF using commercial equipment.

However, the lack of standardized conditions to perform SAR measurements (frequency and field conditions, concentration, etc.) and the effect of different parameters on the heating capacity of the materials (particle size, shape, polydispersity, aggregation, etc.) that are not always easy to characterize, make very difficult to compare results from different research groups. An effort towards the standardization should be promoted by the research community working on magnetic hyperthermia to be able to progress in the understanding of the critical parameters that influence the properties of materials. In this sense, this review shows the important effect of surface modification on the heating properties of the materials.

\section{Conclusions and future perspectives}


MNPs in water are very often aggregated, favoring the appearance of magnetic interactions between particles. These interactions are a critical factor that may either improve or deteriorate the magnetic properties and the applications of MNPs.

Differences in aggregation cause differences in magnetic properties like $\mathrm{DC}$ and $\mathrm{AC}$ susceptibility, coercivity or blocking temperatures. These variations, even if they are small like in the example presented here with the DMSA and PMAO coated MNPs, are enough to originate differences in the heating abilities of MNPs under AMF using commercial equipment. The lack of standardized conditions to perform SAR measurements (frequency and field conditions, concentration, etc.) and the effect of different parameters on the heating capacity of the materials (particle size, shape, polydispersity, aggregation, etc.) that are not always easy to characterize, make very difficult to compare results from different research groups.

Although nanoparticles aggregation is most often deleterious for the application of MNPs, it is possible to control or even tune that clustering through the right choice of the synthetic conditions and the surface modification in order to minimize the problem of aggregation or to transform it in an advantage. Thus, magnetic properties can be enhanced engineering the exchange interactions by means of the preparation of closely aggregated nanoparticles that exhibit continuity of the crystal lattice across the core's boundaries, as in the so called nanoflowers synthesized by the polyol method. Another way is to engineer dipolar interactions through surface modification, or manipulation with an external magnetic field, so MNPs became arranged in an orderly fashion that favors cooperativeness between their magnetic moments improving the heating efficiency.

8

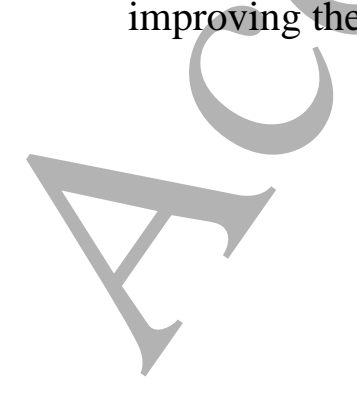


More research to establish experimental procedures to engineer these interactions in a beneficial way (paying special attention to those procedures that are robust, translatable, and easy to scaleup) would be desirable. Also, an effort towards the standardization should be promoted by the research community working on magnetic hyperthermia to be able to progress in the understanding of the critical parameters that influence the properties of materials. In this sense, this paper shows the important effect of surface modification for large MNPs due to magnetic interactions within the aggregates.

\section{ASSOCIATED CONTENT}

Supporting Information.

The following files are available free of charge.

Experimental methods and additional TEM micrographs. (PDF)

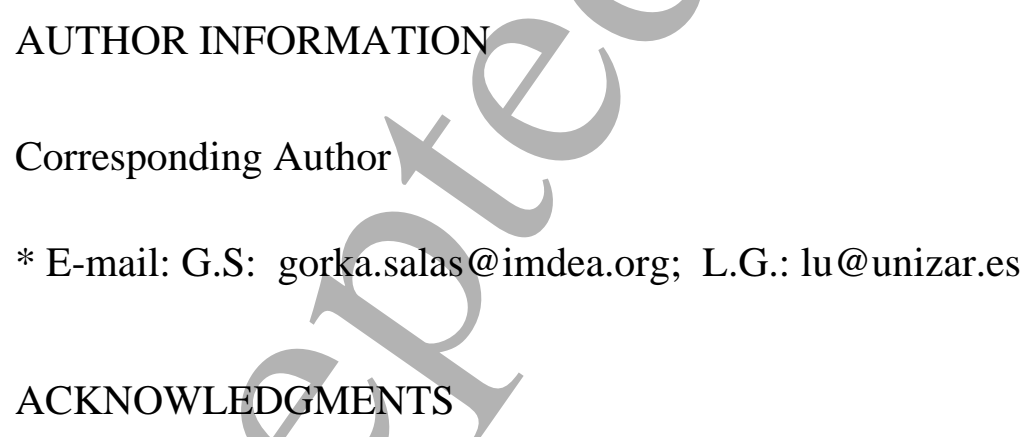

This work was supported by Fondo Social de la DGA (grupos DGA, BIONANOSURF), Ministerio de la Economía y Competitividad del Gobierno de España for the public funding of Proyectos I+D+I - Programa Estatal de Investigación, Desarrollo e Innovación Orientada a los

Retos dé la Sociedad (projects MAT2017-88148-R, MAT2015-71806-R and SAF2014-54763- 
C2-2-R), Comunidad de Madrid (Project NANOFRONTMAG-CM, S2013/MIT-2850), and ERC-Starting Grant 239931-NANOPUZZLE. IMDEA Nanociencia acknowledges support from the 'Severo Ochoa' Programme for Centres of Excellence in R\&D (MINECO, Grant SEV-20160686). LG acknowledges financial support from the Ramón y Cajal subprogram (RYC-201415512). Authors would like to acknowledge the use of Servicio General de Apoyo a la Investigación-SAI, Universidad de Zaragoza.

\section{REFERENCES}

a) Stanicki, D.; Elst, L. Vander; Muller, R. N.; Laurent, S. Synthesis and processing of magnetic nanoparticles. Curr. Opin. Chem. Eng. 2015, 8, 7-14; b) Jeong, U.; Teng, X.; Wang, Y.; Yang, H.; Xia, Y. Superparamagnetic colloids: Controlled synthesis and niche applications. Adv. Mater. 2007, 19, 33-60; c) Lu, A.-H.; Salabas, E. L.; Schüth, F. Magnetic nanoparticles: synthesis, protection, functionalization, and application. Angew. Chemie Int. Ed. English 2007, $46,1222-1244$.

a) Jin, R.; Lin, B.; Li, D.; Ai, H. Superparamagnetic iron oxide nanoparticles for MR imaging and therapy: Design considerations and clinical applications. Curr. Opin. Pharmacol. 2014, 18, 18-27; b) Singh, D.; McMillan, J. M.; Kabanov, A. V; Sokolsky-Papkov, M.; Gendelman, H. E. Bench-to-bedside translation of magnetic nanoparticles. Nanomedicine 2014, 9, 501-516; c) Murdock, N. Nanopharmaceuticals (part 1): products on the market. 2014, 4357-4373; d) Zhu, L.; Zhou, Z.; Mao, H.; Yang, L. Magnetic nanoparticles for precision oncology : theranostic 
magnetic iron oxide nanoparticles for image-guided and targeted cancer therapy. Nanomedicine (Lond.) 2017, 12, 73-87.

${ }^{3}$ Colombo, M.; Carregal-Romero, S.; Casula, M. F.; Gutierrez, L.; Morales, M. P.; Bohm, I. B.; Heverhagen, J. T.; Prosperi, D.; Parak, W. J. Biological applications of magnetic nanoparticles. Chem. Soc. Rev. 2012, 41, 4306-4334.

a) Ruiz, A.; Gutiérrez, L.; Cáceres-Vélez, P. R.; Santos, D.; Chaves, S. B.; Fascineli, M. L.; Garcia, M. P.; Azevedo, R. B.; Morales, M. P. Biotransformation of magnetic nanoparticles as a function of coating in a rat model. Nanoscale 2015, 7, 16321-16329; b) Rojas, J. M.; Gavilán, H.; del Dedo, V.; Lorente-Sorolla, E.; Sanz-Ortega, L.; da Silva, G. B.; Costo, R.; Perez-Yagüe, S.; Talelli, M.; Marciello, M.; Morales, M. P.; Barber, D. F.; Gutiérrez, L. Time-course assessment of the aggregation and metabolization of magnetic nanoparticles. Acta Biomater. 2017, 58, 181-195; c) Martinkova, P.; Brtnicky, M.; Kynicky, J.; Pohanka, M. Iron Oxide Nanoparticles: Innovative Tool in Cancer Diagnosis and Therapy. Adv. Healthc. Mater. 2018, 7, $1-14$.

${ }^{5}$ Bobo, D.; Robinson, K. J.; Islam, J.; Thurecht, K. J.; Corrie, S. R. Nanoparticle-Based Medicines: A Review of FDA-Approved Materials and Clinical Trials to Date. Pharm. Res. 2016, 33, 23732387.

${ }^{\circ}$ Lyklema, H. In Fundamentals of Interface and Colloid Science; Lyklema, H., Ed.; Elsevier Ltd, 2005; Vol. 4, pp. 1-1-1-16.

Gutiérrez, L.; Costo, R.; Grüttner, C.; Westphal, F.; Gehrke, N.; Heinke, D.; Fornara, A.; Pankhurst, Q. A.; Johansson, C.; Veintemillas-Verdaguer, S.; Morales, M. P. Synthesis methods to prepare single- and multi-core iron oxide nanoparticles for biomedical applications. Dalt. Trans. 2015, 44, 2943-2952. 
${ }^{8}$ a) Derjaguin, B. V; Landau, L. Theory of the stability of strongly charged lyophobic sols and of the adhesion of strongly charged particles in solutions of electrolytes. Acta Phys Chim. URSS 1941, 14, 633-662; b) Verwey, E. J. W.; Overbeek, J. T. G. Theory of the stability of lyophobic colloids; Elsevier Publishing Company, Inc.: Leiden, 1948; c) Lin, M. Y.; Lindsay, H. M.; Weitz, D. A.; Ball, R. C.; Klein, R.; Meakin, P. Universality in Colloid Aggregation. Nature $1989,3339,360-362$.

๑ W. B. Russel, D. A. Saville, W. R. Schowalter, Colloidal Dispersions, Cambridge University Press, New York, 1989

${ }^{10}$ Cedervall, T.; Lynch, I.; Lindman, S.; Berggard, T.; Thulin, E.; Nilsson, H.; Dawson, K. A.; Linse, S. Understanding the nanoparticle-protein corona using methods to quantify exchange rates and affinities of proteins for nanoparticles. Proc. Natl. Acad. Sci. 2007, 104, 2050-2055.

"Walkey, C. D.; Chan, W. C. W. Understanding and controlling the interaction of nanomaterials with proteins in a physiological environment. Chem. Soc. Rev. 2012, 41, 2780-2799.

${ }^{12}$ Yallapu, M. M.; Chauhan, N.; Othman, S. F.; Khalilzad-Sharghi, V.; Ebeling, M. C.; Khan, S.; Jaggi, M.; Chauhan, S. C. Implications of protein corona on physico-chemical and biological properties of magnetic nanoparticles. Biomaterials 2015, 46, 1-12.

${ }^{13}$ Wells, M. A.; Abid, A.; Kennedy, I. M.; Barakat, A. I. Serum proteins prevent aggregation of Fe2O3 and $\mathrm{ZnO}$ nanoparticles. Nanotoxicology 2012, 6, 837-846.

${ }^{14}$ Díaz, B.; Sánchez-Esspinel, C.; Arruebo, M.; Faro, J.; De Miguel, E.; Magadán, S.; Yagüe, C.; Fernández-Pacheco, R.; Ibarra, M. R.; Santamaría, J.; González-Fernández, Á. Assessing methods for blood cell cytotoxic responses to inorganic nanoparticles and nanoparticle aggregates. Small 2008, 4, 2025-2034. 
"s Stepien, G.; Moros, M.; Pérez-Hernández, M.; Monge, M.; Gutiérrez, L.; Fratila, R. M.; Las Heras, M. De; Menao Guillén, S.; Puente Lanzarote, J. J.; Solans, C.; Pardo, J.; De La Fuente, J. M. Effect of surface chemistry and associated protein corona on the long-term biodegradation of iron oxide nanoparticles in Vivo. ACS Appl. Mater. Interfaces 2018, 10, 4548-4560.

${ }^{16}$ Wang, F.; Yu, L.; Monopoli, M. P.; Sandin, P.; Mahon, E.; Salvati, A.; Dawson, K. A. The biomolecular corona is retained during nanoparticle uptake and protects the cells from the damage induced by cationic nanoparticles until degraded in the lysosomes. Nanomedicine Nanotechnology, Biol. Med. 2013, 9, 1159-1168.

${ }^{\text {" Huynh, K. A.; Chen, K. L. Aggregation kinetics of citrate and polyvinylpyrrolidone coated }}$ silver nanoparticles in monovalent and divalent electrolyte solutions. Environ. Sci. Technol. $2011,45,5564-5571$.

${ }^{18}$ Pfeiffer, C.; Rehbock, C.; Huhn, D.; Carrillo-Carrion, C.; de Aberasturi, D. J.; Merk, V.; Barcikowski, S.; Parak, W. J. Interaction of colloidal nanoparticles with their local environment: the (ionic) nanoenvironment around nanoparticles is different from bulk and determines the physico-chemical properties of the nanoparticles. J. R. Soc. Interface 2014, 11, 2013093120130931.

19 Harris, L. A.; Goff, J. D.; Carmichael, A. Y.; Riffle, J. S.; Harburn, J. J.; St. Pierre, T. G.; Saunders, M. Magnetite nanoparticle dispersions stabilized with triblock copolymers. Chem. Mater. 2003, 15,1367-1377.

${ }^{20}$ Pardoe, H.; Chua-anusorn, W.; St. Pierre, T. G.; Dobson, J. Structural and magnetic properties of nanoscale iron oxide particles synthesized in the presence of dextran or polyvinyl alcohol. $J$. Magn. Magn. Mater. 2001, 225, 41-46. 
${ }^{21}$ Di Corato, R.; Espinosa, A.; Lartigue, L.; Tharaud, M.; Chat, S.; Pellegrino, T.; Ménager, C.; Gazeau, F.; Wilhelm, C. Magnetic hyperthermia efficiency in the cellular environment fordifferent nanoparticle designs. Biomaterials 2014, 35, 6400-6411.

${ }^{22}$ Fortin, J.-P.; Wilhelm, C.; Servais, J.; Ménager, C.; Bacri, J.-C.; Gazeau, F. Size-sórted anionic iron oxide nanomagnets as colloidal mediators for magnetic hyperthermia. J. Am. Chem. Soc. 2007, 129, 2628-2635.

${ }^{23}$ a) Li, Z.; Li, D.; Hao, D.; Cheng, Y. Study on the creep and recovery/behaviors of ferro fluids. Smart Mater. Struct. 2017, 26, 105022; b) Liang, J.; Du, N.; Song, S.; Hou, W. Magnetic demulsification of diluted crude oil-in-water nanoemulsions using oleic acid-coated magnetite nanoparticles. Colloids Surfaces A Physicochem. Eng. Asp. 2015, 466, 197-202; c) Liang, J.; Li, H.; Yan, J.; Hou, W. Demulsification of Oleic-Acid-Coated Magnetite Nanoparticles for Cyclohexane-in-Water Nanoemulsions. Energy Fuels 2014, 28, 6172-6178; d) Raj, K.; Moskowitz, R. Commercial applications of ferrofluids. J. Magn. Magn. Mater. 1990, 85, 233245.

${ }^{24}$ Some selected references on the DMSA coated nanoparticles for biomedical applications are: a) Mou, Y.; Zhou, J.; Xiong, F.; Li, H.; Sun, H.; Han, Y.; Gu, N.; Wang, C. Effects of 2,3dimercaptosuccinic acid modified Fe2O3 nanoparticles on microstructure and biological activity of cardiomyocytes. RSC Adv. 2015, 5, 19493-19501; b) Kossatz, S.; Ludwig, R.; Dähring, H.; Ettelt, V.; Rimkus, G.; Marciello, M.; Salas, G.; Patel, V.; Teran, F. J.; Hilger, I. High Therapeutic Efficiency of Magnetic Hyperthermia in Xenograft Models Achieved with Moderate Temperature Dosages in the Tumor Area. Pharm. Res. 2014, 31, 3274-3288.; c) Durmus, N. G.; Taylor, E. N.; Kummer, K. M.; Webster, T. J. Enhanced Efficacy of Superparamagnetic Iron Oxide Nanoparticles Against Antibiotic-Resistant Biofilms in the Presence of Metabolites. Adv. Mater. 2013, 25, 5706-5713; d) Liang, G.; Xiao, L.; Chen, H.; Liu, Q.; Zhang, S.; Li, F.; Kong, J. Biosensors and Bioelectronics Label-free, nucleotide-mediated dispersion of magnetic 
nanoparticles for "“ non-sandwich type "” MRI-based quantification of enzyme. Biosens. Bioelectron. 2013, 41, 78-83; Wu, Y.; Song, M.; e) Xin, Z.; Zhang, X.; Zhang, Y.; Cho, M. H.; Lee, E. J.; Son, M.; Lee, J.; Yoo, D.; Kim, J.; Park, S. W.; Shin, J.; Cheon, J. A magnetic switch for the control of cell death signalling in in vitro and in vivo systems. Nat. Mater. 2012, 11, 1038-1043.; f) Wang, C.; Li, S.; Gu, N. Ultra-small particles of iron oxide as peroxidase for immunohistochemical detection. Nanotechnology 2011, 22, 225703; g) Dilnawaz, F.; Singh, A.; Mohanty, C.; Sahoo, S. K. Biomaterials Dual drug loaded superparamagnetic iron oxide nanoparticles for targeted cancer therapy. Biomaterials 2010, 31, 3694-3706; h) Huh, Y.-M.; Jun, Y.; Song, H.-T.; Kim, S.; Choi, J.; Lee, J.-H.; Yoon, S.; Kim, K.; Shin, J.-S.; Suh, J.-S.; Cheon, J. In vivo magnetic resonance detection of cancer by using multifunctional magnetic nanocrystals. J. Am. Chem. Soc. 2005, 127, 12387-12391.

${ }^{25}$ A recent review on MNPs coated with DMSA for biomedical applications can be found in: Ruiz, A.; Morais, P. C.; Bentes de Azevedo, R.; Lacava, Z. G. M.; Villanueva, A.; Morales, M. P. Magnetic nanoparticles coated with dimercaptosuccinic acid: development, characterization, and application in biomedicine. J. Nanoparticle Res. 2014, 16, 2589.

${ }^{26}$ a) Moros, M.; Ambrosone, A.; Stepien, G.; Fabozzi, F.; Marchesano, V.; Castaldi, A.; Tino, A.; de la Fuente, J. M.; Tortiglione, C. Deciphering intracellular events triggered by mild magnetic hyperthermia in vitro and in vivo. Nanomedicine (Lond.) 2015, 10, 2167-2183; b) Heine, M.; Bartelt, A.; Bruns, O. T.; Bargheer, D.; Giemsa, A.; Freund, B.; Scheja, L.; Waurisch, C.; Eychmüller, A.; Reimer, R.; Weller, H.; Nielsen, P.; Heeren, J. The cell-type specific uptake of polymer-coated or micelle-embedded QDs and SPIOs does not provoke an acute proinflammatory response in the liver. Beilstein J. Nanotechnol. 2014, 5, 1432-1440; c) Moros, M.; Pelaz, B.; López-Larrubia, P.; García-Martin, M. L.; Grazú, V.; de la Fuente, J. M. Engineering biofunctional magnetic nanoparticles for biotechnological applications. Nanoscale 2010, 2, 1746-1755. 
${ }_{27}$ Yantasee, W.; Warner, C. L.; Sangvanich, T.; Addleman, R. S.; Carter, T. G.; Wiacek, R. J.; Fryxell, G. E.; Timchalk, C.; Warner, M. G. Removal of heavy metals from aqueous systems with thiol functionalized superparamagnetic nanoparticles. Environ. Sci. Technol. 2007, 41, 5114-5119.

${ }^{28}$ Kloust, H.; Schmidtke, C.; Feld, A.; Schotten, T.; Eggers, R.; Fittschen, U. E. A.; Schulz, F.; Pöselt, E.; Ostermann, J.; Bastús, N. G.; Weller, H. In situ functionalization and PEO coating of iron oxide nanocrystals using seeded emulsion polymerization. Langmuir 2013, 29, 4915-4921.

${ }^{29}$ Li, L.; Jiang, W.; Luo, K.; Song, H.; Lan, F.; Wu, Y.; Gu, Z. Superparamagnetic iron oxide nanoparticles as MRI contrast agents for non-invasive stem cell labeling and tracking. Theranostics 2013, 3, 595-615.

${ }^{30}$ Bohara, R. A.; Thorat, N. D.; Pawar, S. H. Role of functionalization: strategies to explore potential nano-bio applications of magnetic nanoparticles. RSC Adv. 2016, 6, 43989-44012.

${ }^{31}$ Xu, C.; Xu, K.; Gu, H.; Zheng, R.; Liu, H.; Zhang, X.; Guo, Z.; Xu, B. Dopamine as a robust anchor to immobilize functional molecules on the iron oxide shell of magnetic nanoparticles. $J$. Am. Chem. Soc. 2004, 126, 9938-9939.

${ }^{32}$ Song, H. T.; Choi, J. S.; Huh, Y. M.; Kim, S.; Jun, Y. W.; Sun, J. S.; Cheon, J. Surface modulation of magnetic nanocrystals in the development of highly efficient magnetic resonance probes for intracellular labeling. J. Am. Chem. Soc. 2005, 127, 9992-9993.

${ }^{33}$ Song, H. T.; Choi, J. S.; Huh, Y. M.; Kim, S.; Jun, Y. W.; Sun, J. S.; Cheon, J. Surface modulation of magnetic nanocrystals in the development of highly efficient magnetic resonance probes for intracellular labeling. J. Am. Chem. Soc. 2005, 127, 9992-9993. 
${ }^{34}$ Lee, I. S.; Lee, N.; Park, J.; Kim, B. H.; Yi, Y. W.; Kim, T.; Kim, T. K.; Lee, I. H.; Paik, S. R.; Hyeon, T. Ni/NiO core/shell nanoparticles for selective binding and magnetic/separation of histidine-tagged proteins. J. Am. Chem. Soc. 2006, 128, 10658-10659.

${ }^{35}$ Jun, Y.-W.; Huh, Y.-M.; Choi, J.-S.; Lee, J.-H.; Song, H.-T.; Kim, S.; Yoon, S.; Kim, K.-S.; Shin, J.-S.; Suh, J.-S.; Cheon, J. Nanoscale size effect of magnetic nanocrystals and their utilization for cancer diagnosis via magnetic resonance imaging. J. Am. Chem. Soc. 2005, 127, $5732-5733$.

${ }^{36}$ Lee, N.; Choi, Y.; Lee, Y.; Park, M.; Moon, W. K.; Choi, S. H.; Hyeon, T. Water-dispersible ferrimagnetic iron oxide nanocubes with extremely high r2relaxivity for highly sensitive in vivo MRI of tumors. Nano Lett. 2012, 12, 3127-3131.

${ }^{37}$ Lalatonne, Y.; Richardi, J.; Pileni, M. P. Van der Waals versus dipolar forces controlling mesoscopic organizations of magnetic nanocrystals. Nat. Mater. 2004, 3, 121-125.

${ }^{38}$ Serantes, D.; Baldomir, D.; Martinez-Boubeta, C.; Simeonidis, K.; Angelakeris, M.; Natividad, E.; Castro, M.; Mediano, A.; Chen, D.-X,; Sanchez, A.; Balcells, L.; Martínez, B. Influence of dipolar interactions on hyperthermia properties of ferromagnetic particles. J. Appl. Phys. 2010, 108, 073918; b) Serantes, D.; Simeonidis, K.; Angelakeris, M.; Chubykalo-Fesenko, O.; Marciello, M.; Del Puerto Morales, M.; Baldomir, D.; Martinez-Boubeta, C. Multiplying magnetic hyperthermia response by nanoparticle assembling. J. Phys. Chem. C 2014, 118, $5927-5934$.

${ }^{39}$ Nadeem, K.; Krenn, H.; Traussnig, T.; Würschum, R.; Szabó, D. V.; Letofsky-Papst, I. Effect of dipolar and exchange interactions on magnetic blocking of maghemite nanoparticles. J. Magn. Magn. Mater. 2011, 323, 1998-2004. 
${ }^{40}$ a) Jonsson, T.; Mattsson, J.; Djurberg, C.; Khan, F. A.; Nordblad, P.; Svedlindh, P. Aging in a magnetic particle system. Phys. Rev. Lett. 1995, 75, 4138-4141; b) Jonsson, T.; Nordblad, P.; Svedlindh, P. Dynamic study of dipole-dipole interaction effects in a magnetic nanoparticle system. Phys. Rev. B - Condens. Matter Mater. Phys. 1998, 57, 497-504; c) López, A.; Gutiérrez, L.; Lázaro, F. J. The role of dipolar interaction in the quantitativel determination of particulate magnetic carriers in biological tissues. Phys. Med. Biol. 2007, 52, 5043-5056; d) Gutiérrez, L.; Mejías, R.; Barber, D. F.; Veintemillas-Verdaguer, S.; Serna, C. J.; Lázaro, F. J.; Morales, M. P. Ac magnetic susceptibility study of in vivo nanoparticle biodistribution. J. Phys. D. Appl. Phys. $2011,44$.

${ }^{4}$ Gavilán, H.; Sánchez, E. H.; Brollo, M. E. F.; Asín, L.; Moerner, K. K.; Frandsen, C.; Lázaro, F. J.; Serna, C. J.; Veintemillas-Verdaguer, S.; Morales, M. P.; Gutiérrez, L. Formation Mechanism of Maghemite Nanoflowers Synthesized by a Polyol-Mediated Process. ACS Omega $2017,2,7172-7184$.

${ }_{42}$ Javed, Y.; Lartigue, L.; Hugounenq, P.; Vuong, Q. L.; Gossuin, Y.; Bazzi, R.; Wilhelm, C.; Ricolleau, C.; Gazeau, F.; Alloyeau, D. Biodegradation mechanisms of iron oxide monocrystalline nanoflowers and tunable shield effect of gold coating. Small 2014, 10, 33253337.

${ }^{43}$ Sharma, R.; Lamba, S.; Annapoorni, S. Magnetic properties of polypyrrole-coated iron oxide nanoparticles. J. Phys. D. Appl. Phys. 2005, 38, 3354-3359.

${ }^{44}$ Sun, J.; Fan, F.; Wang, P.; Ma, S.; Song, L.; Gu, N. Orientation-Dependent Thermogenesis of Assembled Magnetic Nanoparticles in the Presence of an Alternating Magnetic Field.

ChemPhysChem 2016, 17, 3377-3384. 
${ }^{4 s}$ a) Bae, C. J.; Angappane, S.; Park, J. G.; Lee, Y.; Lee, J.; An, K.; Hyeon, T. Experimental studies of strong dipolar interparticle interaction in monodisperse $\mathrm{Fe} 3 \mathrm{O} 4$ nanoparticles. Appl. Phys. Lett. 2007, 91, 4-6; b) Haase, C.; Nowak, U. Role of dipole-dipole interactions for hyperthermia heating of magnetic nanoparticle ensembles. Phys. Rev. B-Condens. Matter Mater. Phys. 2012, 85, 2-6; c) Lartigue, L.; Hugounenq, P.; Alloyeau, D.; Clarke, S. P.; Lévy, M.; Bacri, J.-C.; Bazzi, R.; Brougham, D. F.; Wilhelm, C.; Gazeau, F. Cooperative organization in iron oxide multi-core nanoparticles potentiates their efficiency as heating mediators and MRI contrast agents. ACS Nano 2012, 6, 10935-10949; d) Lima, E.; De Biasi, E.; Mansilla, M. V.; Saleta, M. E.; Granada, M.; Troiani, H. E.; Effenberger, F. B.; Rossi, L. M.; Rechenberg, H. R.; Zysler, R. D. Heat generation in agglomerated ferrite nanoparticles in an alternating magnetic field. J. Phys. D. Appl. Phys. 2013, 46, 45002.; e) Branquinho, L. C.; Carrião, M. S.; Costa, A. S.; Zufelato, N.; Sousa, M. H.; Miotto, R.; Ivkov, R.; Bakuzis, A. F. Effect of magnetic dipolar interactions on nanoparticle heating efficiency: implications for cancer hyperthermia. Sci. Rep. 2013, 3, 2887; f) Salas, G.; Camarero, J.; Cabrera, D.; Takacs, H.; Varela, M.; Ludwig, R.; Dähring, H.; Hilger, I.; Miranda, R.; Morales, M. D. P.; Teran, F. J. Modulation of magnetic heating via dipolar magnetic interactions in monodisperse and crystalline iron oxide nanoparticles. J. Phys. Chem. C 2014, 118, 19985-19994; g) De La Presa, P.; Luengo, Y.; Velasco, V.; Morales, M. P.; Iglesias, M.; Veintemillas-Verdaguer, S.; Crespo, P.; Hernando, A. Particle interactions in liquid magnetic colloids by zero field cooled measurements: Effects on heating efficiency, J. Phys. Chem. C 2015, 119, 11022-11030.; h) Ovejero, J. G.; Cabrera, D.; Carrey, J.; Valdivielso, T., Salas, G.; Teran, F. J. Effects of inter- and intra-aggregate magnetic dipolar interactions on the magnetic heating efficiency of iron oxide nanoparticles. Phys. Chem. Chem. Phys. 2016, 18, 10954-10963.

${ }^{4}$ Salas, G.; Veintemillas-Verdaguer, S.; Morales, M. del P. Relationship between physicochemical properties of magnetic fluids and their heating capacity. Int. J. Hyperth. 2013, 29, $768-776$. 
${ }^{47}$ a) Berkov, D. V; Gorn, N. L. Susceptibility of the disordered system of fine magnetic particles: a Langevin-dynamics study. J. Phys. Condens. Matter 2001, 13, 9369-9381.; b) Goya, G. F.; Berquó, T. S.; Fonseca, F. C.; Morales, M. P. Static and dynamic magnetic properties of spherical magnetite nanoparticles. J. Appl. Phys. 2003, 94, 3520-3528; b) Mørup, S.; Hansen, M. F.; Frandsen, C. Magnetic interactions between nanoparticles. Beilstein J. Nanotechnol. 2010, 1, 182-190.

${ }^{48}$ Materia, M. E.; Guardia, P.; Sathya, A.; Pernia Leal, M.; Marotta, R.; Di Corato, R.; Pellegrino, T. Mesoscale assemblies of iron oxide nanocubes as heat mediators and image contrast agents. Langmuir 2015, 31, 808-816.

${ }^{49}$ Coral, D. F.; Mendoza Zélis, P.; Marciello, M.; Morales, M. D. P.; Craievich, A.; Sánchez, F. H.; Fernández Van Raap, M. B. Effect of Nanoclustering and Dipolar Interactions in Heat Generation for Magnetic Hyperthermia. Langmuir 2016, 32, 1201-1213.

so a) Martinez-Boubeta, C.; Simeonidis, K.; Serantes, D.; Conde-Leborán, I.; Kazakis, I.; Stefanou, G.; Peña, L.; Galceran, R.; Balcells, L.; Monty, C.; Baldomir, D.; Mitrakas, M.; Angelakeris, M. Adjustable Hyperthermia Response of Self-Assembled Ferromagnetic Fe-MgO Core-Shell Nanoparticles by Tuning Dipole-Dipole Interactions. Adv. Funct. Mater. 2012, 22, 3737-3744; b) Martinez-Boubeta, C.; Simeonidis, K.; Makridis, A.; Angelakeris, M.; Iglesias, O.; Guardia, P.; Cabot, A.; Yedra, L.; Estrade, S.; Peiro, F.; Saghi, Z.; Midgley, P. A.; CondeLeboran, I.; Serantes, D.; Baldomir, D. Learning from Nature to Improve the Heat Generation of Iron-Oxide Nanoparticles for Magnetic Hyperthermia Applications. Sci. Rep. 2013, 3, 1652; c) Conde-Leboran, I.; Baldomir, D.; Martinez-Boubeta, C.; Chubykalo-Fesenko, O.; Del Puerto Morales, M.; Salas, G.; Cabrera, D.; Camarero, J.; Teran, F. J.; Serantes, D. A Single Picture Explains Diversity of Hyperthermia Response of Magnetic Nanoparticles. J. Phys. Chem. C $2015,119,15698-15706$. 
${ }^{51}$ Niculaes, D.; Lak, A.; Anyfantis, G. C.; Marras, S.; Laslett, O.; Avugadda, S. K.; Cassani, M.; Serantes, D.; Hovorka, O.; Chantrell, R.; Pellegrino, T. Asymmetric Assembling of Iron Oxide Nanocubes for Improving Magnetic Hyperthermia Performance. ACS Nano 2017, 11, 1212112133.

${ }^{52}$ Andreu, I.; Natividad, E.; Solozábal, L.; Roubeau, O. Nano-objects for addressing the control of nanoparticle arrangement and performance in magnetic hyperthermia. ACS Nano 2015, 9, $1408-1419$.

${ }^{53}$ Hu, K.; Sun, J.; Guo, Z.; Wang, P.; Chen, Q.; Ma, M.; Gu, N. A Novel Magnetic Hydrogel with Aligned Magnetic Colloidal Assemblies Showing Controllable Enhancement of Magnetothermal Effect in the Presence of Alternating Magnetic Field. Adv. Mater. 2015, 27, 2507-2514.

${ }^{54}$ Sun, J.; Fan, F.; Wang, P.; Ma, S.; Song, L.; Gu, N. Orientation-Dependent Thermogenesis of Assembled Magnetic Nanoparticles in the Presence of an Alternating Magnetic Field.

ChemPhysChem 2016, 17, 3377-3384.

${ }^{55}$ Guibert, C.; Dupuis, V.; Peyre, V.; Fresnais, J. Hyperthermia of Magnetic Nanoparticles: Experimental Study of the Role of Aggregation. J. Phys. Chem. C 2015, 119, 28148-28154.

${ }^{56}$ Ludwig, R.; Stapf, M.; Dutz, S.; Müller, R.; Teichgräber, U.; Hilger, I. Structural properties of magnetic nanoparticles determine their heating behavior - an estimation of the in vivo heating potential. Nanoscale Res. Lett. 2014, 9, 602.

${ }^{57}$ Liu, X. L.; Fan, H. M.; Yi, J. B.; Yang, Y.; Choo, E. S. G.; Xue, J. M.; Fan, D. Di; Ding, J. Optimization of surface coating on Fe3O4 nanoparticles for high performance magnetic hyperthermia agents. J. Mater. Chem. 2012, 22, 8235. 